\title{
How Angel Know-How Shapes Ownership Sharing in Stage-Based Contracts
}

\author{
S. Sinan Erzurumlu', Nitin Joglekar², \\ Moren Lévesque ${ }^{3}$, and Fehmi Tanrisever ${ }^{4}$
}

\begin{abstract}
We draw upon stewardship theory to formally derive bounds on the investment amount in a business prospect, and to characterize ownership sharing when investors offer two-stage financing along with know-how to increase the prospect's valuation. In the early-development stage, we show that the direct effect of investor know-how increases the entrepreneur's share while the indirect effect from that know-how due to its interaction with the investment size, decreases it. In the subsequent growth stage, the direct effect decreases the entrepreneur's share while the indirect effect increases it. These tradeoffs offer theoretical and practical implications for writing investment contracts involving investor know-how.
\end{abstract}

\section{Keywords}

stage-based contract, investor know-how, value creation, angel investors, stewardship theory, empirical analysis, mathematical analysis

While the extant literature on stage-based investment contracts focuses mainly on agency issues such as adverse selection and moral hazard (see a review by Burchardt, Hommel, Kamuriwo, \& Billitteri, 2014), scholarly analysis of start-up investment data has shown that firms' pre-investment valuation is positively associated with increases in angel investors' human capital captured through their education and experience (for related evidence on Belgian angel-backed ventures, see Collewaert \& Manigart, 2016). However, theories on developing contracts based on such value creation do not agree on how this gain in valuation should be divided among the parties - the investor and entrepreneur. Resolving these theoretical disagreements is important because a deeper understanding of the division of value created can stimulate the entrepreneur to seek an investor with the know-how that can enhance the venture's alignment with market mechanisms and further align the goal of the investor with that of the entrepreneur, which in turn would render both parties better off.

\footnotetext{
'Olin School of Business, Babson College, Babson Park, MA, USA

${ }^{2}$ Questrom School of Business, Boston University, Boston, MA, USA

${ }^{3}$ Schulich School of Business, York University, Toronto, ON, Canada

${ }^{4}$ Faculty of Business Administration, Bilkent University, Ankara, Turkey
}

\section{Corresponding Author:}

Moren Lévesque, Schulich School of Business, York University, 4700 Keele Street, Toronto, ON M3J IP3, Canada.

Email: mlevesque@schulich.yorku.ca 
The objective of this research is to investigate how stage-based contracts should be structured ex-ante if the value created from either the development work in the early stage (development), or growth work during the subsequent stage (growth) is conditioned upon the level of know-how that the investor brings to the venture. For development stage 1, such know-how may help entrepreneurs to overcome technological issues, determine the technology's market value or better articulate the technology's contribution through the investor's access to intellectual property and networks, while for stage 2 the investor's technological knowledge and networks can provide the entrepreneur the agility to rapidly respond to developing issues and to competitors (Wiklund \& Shepherd, 2003).

We reach our research objective by seeking a deeper understanding of entrepreneurinvestor ownership sharing in a stage-based contract from the stewardship perspective (Davis, Schoorman, \& Donaldson, 1997; Fox \& Hamilton, 1994; Wasserman, 2006), which stipulates that goals between the investor and entrepreneur are aligned (Morck, Shleifer, \& Vishny, 1988). Several stages of funding provide opportunities for goal alignment between the two parties that can result in a lower likelihood of agency issues than when only one stage of funding is available (Arthurs \& Busenitz, 2003). This holds because the entrepreneur has the chance to validate after the early stage(s) whether he or she can build trust in the relationship and rely on the investor's know-how to foster growth and to increase valuation. We build on this perspective to argue that, if the addition of investor know-how in either the first or second stage (early venture development or growth, respectively) is expected to create value, the entrepreneur should be allocated ex-ante a larger ownership share. Investors who adopt such a perspective and possess valuable know-how should be willing to initially agree on a smaller ownership share because the expected size of the entire pie - the firm's valuation - will grow, thanks, in part, to their know-how. This increased valuation would counterbalance their reduced ownership share, while keeping each party's goal aligned. This arrangement motivates both the entrepreneur to work hard to launch the start-up and the investor to assist with the development (first stage) and growth (second stage) with their know-how.

Drawing upon the stewardship theory, Collewaert and Manigart (2016) offer support for this ownership-share rationale for angel investors by showing that when angels possess high levels of know-how, they tend to negotiate higher firm valuations. Consistent with this perspective, we first use mathematical modeling (i.e., a two-stage decision framework) to capture the investor's financial incentives (through mathematical constraints) and to characterize ownership sharing that can provide a compelling incentive to the investor (by satisfying the constraints). This approach enables us to propose a lower bound (i.e., total cash needed) beyond which contracts that require deferral of a portion of the investment to the second stage should be favored. We also specify a lower bound for the investor's know-how (i.e., value-creation ability) at the first stage to account for the risk of discontinuing the new investment opportunity. Moreover, we identify the sign for the relationship between ownership sharing and investor know-how at both stages, while satisfying the incentive constraints, which enables us to articulate rationales for the respective relationships. And, consistent with the stewardship theory, for both stages we posit that the interaction between the investment amount and the level of investor know-how positively affects the entrepreneur's ownership share.

The formal framework also delivers a mathematical expression that we transform into a specification for a regression study. We apply this specification to a dataset of 85 angel investment contracts from the Angel Investor Performance Project (AIPP) to test the posited relationships. Our analysis of the AIPP data demonstrates that the derived lower bound on total cash needed, beyond which a portion of the investment should be deferred to the second stage, is observed in practice with high accuracy. From a theory perspective, the empirical 
results present a nuanced description of the observed contracts. When considering the direct relationship between investor know-how and the entrepreneur's ownership share, the stewardship-based prescription is supported but only during stage 1 . However, when considering the moderation effect of the contracted investment size (amount of money invested) on this direct relationship, the stewardship-based prescription is supported but only during stage 2 . A refinement of our empirical analysis also demonstrates that this effect is better specified as a moderated mediation.

In essence, we employ the stewardship theory to illustrate that when determining the entrepreneur's ownership share in a start-up contract, the amount of funds invested moderates the mediating effect on that share of the investor's amount of know-how brought to both stages of the contract. This contribution is important for three reasons. First, it extends the stewardship theory by identifying the role that investor know-how plays in supporting startups by granting entrepreneurs a larger ownership share across the two stages of a new business prospect. Second, it extends the debate on the limits of the stewardship theory (Arthurs \& Busenitz, 2003) in the know-how realm, in that we illustrate conditions when prescriptions based on the stewardship theory are insufficient to explain the variation in the contracts we sampled. Third, it illustrates that the derived bounds on the investment size work well for two-stage contracts involving investor know-how. These bounds can influence the contract process, because investors who are willing to collaborate by ceding the stewardship role to the entrepreneurs can draw upon these bounds as managerial guidance for structuring their contracts. We also document elasticity values and tradeoffs between levels of investor know-how and investment size that are germane to writing such contracts.

This work therefore extends the stewardship theory into the realm of know-how contracting to examine a body of evidence on structuring stage-based contracts ex-ante if the value created from either early-stage work or follow-on, growth-related work is conditioned upon the level of know-how that the investor brings to the venture. The role of both, the investment amount and who provides it (i.e., in terms of the investor's level of know-how delivered at stages 1 and 2), which we identify, also appear to challenge some research findings, including Freedman (2012) who reported that "[i]t's not the amount of money you raise, it's who you raise it from" (p. 80).

\section{Theoretical Framework}

We utilize a two-stage decision-theoretic model to study entrepreneur-investor ownership sharing in a two-stage contract based on the stewardship theory. This model can directly capture an investor's appropriate financial incentives to first enter into the investment deal and, contingent on key outcomes of the enterprise, to remain with the deal. It also enables us to explicitly characterize the entrepreneur's ownership share so as to provide compelling incentives to the investor and optimize the entrepreneur's payoff as a portion of the value created. This characterization facilitates the formulation, rationalization, and testing of hypotheses consistent with the stewardship perspective. We can thus examine how two-stage contracts should be structured ex-ante when the value created from both stage 1 and stage 2 is conditioned upon the investor's know-how. We do so by first devising a formal model that endogenously characterizes ownership sharing, where know-how is a key determinant of firm valuation (Collewaert \& Manigart, 2016).

The need for an investor's specialized know-how at various stages of venture creation is documented in angel financing studies (e.g., Wong, Bhatia, \& Freeman, 2009; Maxwell, Jeffrey, \& Lévesque, 2011). In the first stage of the business prospect (the development stage), an investor's early-stage know-how is associated with knowledge and expertise that 
can inform product development to advance the new business (e.g., by increasing the entrepreneur's ability to articulate the technology's value and contribution). At the growth stage, an investor's growth-related know-how corresponds to technological knowledge and expertise as well as network access (e.g., to enable the entrepreneur to promptly react to competitors). Pahnke, Katila, and Eisenhardt (2015) inspired this division of know-how in two stages by arguing that entrepreneurs must carefully consider the benefits and risks associated with different types of investors with whom they build a relationship, because the investor type that can aid innovation development may differ from the type that can aid in later stages.

However, for any given investor, the value created by this know-how remains uncertain because its actual realization is deal-specific and unknown a priori. Our formalization thus incorporates two (nonnegative) uncertain levels of deal-specific know-how delivered by the investor during stage 1 and stage $2, L_{1}$ and $L_{2}$, respectively. We use two uniformly distributed random variables with, respectively, support $[0, \mu]$ and $[0, \nu]$ to represent these two levels $(\mu / 2$ and $v / 2$ capture their expected values). That is, the investor's know-how during stage 1 can reach any level between 0 and $\mu$ with identical probability, while it can reach any level between 0 and $v$ during stage 2 , also with identical probability. ${ }^{1}$

To further differentiate the stages, we consider the output elasticity of these respective levels of know-how, which is captured by exponent $a$ for the investor's know-how at stage 1 and by exponent $b$ for stage 2 . The contribution to firm valuation is thus $L_{1}^{a}$ and $L_{2}^{b}$ from the investor. As Collewaert and Manigart (2016) show, as this human capital in the form of investor know-how increases, so does the overall value of the firm. We denote this value by $V$, which takes the form of a Cobb-Douglas production function. The resulting multiplicative form of the firm's value function is desirable because it considers the dependence of the investor's stage-based contributions and also the complementarity of these contributions (e.g., Shane \& Cable, 2002). Moreover, the exponents ( $a$ and $b$ ) accounting for the impact of each input (i.e., the investor's stage-based contribution) provide flexibility on the shape of this function. Formally, $V\left(p, L_{1}, L_{2}\right)=p L_{1}^{a} L_{2}^{b}$, where $a \in(0,1)$ and $b \in(0,1)$ capture decreasing returns from know-how, with $p$ being a productivity factor. The (deal-specific) productivity factor is a scaling measure that turns the bundle of know-how from the investor into a valuable outcome (Lichtenstein \& Brush, 2001; Nesta \& Saviotti, 2006), which has been operationalized in terms of the entrepreneur's value creation ability (van Praag \& Versloot, 2007). This factor also accounts for the frequency of investor-entrepreneur interactions.

Based on this factor, our proposed formal framework emphasizes that not only does investor know-how create value, but so does the entrepreneur's and investor's engagement in the enterprise. However, to investigate how the investor's know-how shapes ownership sharing in a two-stage contract, we must tease out the impact of such know-how. Hence, as we develop testable hypotheses, we pay more attention to the investor's know-how delivered during both stages (development and growth), than to the productivity factor. Moreover, for ease of inference, we set the value function $V\left(p, L_{1}, L_{2}\right)$ to be independent of the investment size, and we account for an investment-size effect based on the costs that the entrepreneur pays back to the investor conditioned on this valuation. This separation between revenue-driven payback, asset size, and investment are evident in many industries (e.g., energy, software and medical devices; see Lévesque, Joglekar, \& Davies, 2012), thus we control for industry in the empirical exercise. ${ }^{2}$

Davis et al. (1997) argue that the stewardship theory applies to "situations in which managers are not motivated by individual goals, but rather are stewards whose motives are aligned with the objectives of their principals" (p. 21). Within this stewardship-based framing of know-how provided by the investor, the entrepreneur shares the overall value $V\left(p, L_{1}, L_{2}\right)$ with the investor through a contract designed for such know-how. To achieve our objective 
of offering a deeper understanding of entrepreneur-investor ownership sharing in a two-stage contract from the stewardship theory perspective, we first explicitly characterize ownership sharing and funding allocation between stage 1 (development) and stage 2 (growth) contingent on investor know-how. Following the lead of Repullo and Suarez (2004) and Wang and Zhou (2004), in our setting some interim information on the investment opportunity is verifiable so that both parties can sign the initial contract a priori. Then, contingent on the resulting anticipated increased valuation based on the investor's know-how, a subsequent cash infusion can take place in stage 2. Our formulation differs from that of Repullo and Suarez (2004) and Wang and Zhou (2004) by simultaneously: (a) endogenizing the cash allocation based on the investor's know-how, (b) making the entrepreneur a decision-maker who aims to assess the investor's value-creation ability, and (c) creating value through human capital in the form of investor know-how at two stages (development and growth) and through a productivity factor associated with the entrepreneur transforming this bundle of know-how into value for the venture.

As the decision-maker, the entrepreneur in our setting holds the bargaining power. This assumption mirrors a scenario where the entrepreneur can request a commitment from the investor up front to guarantee that funding will also be transferred during the following round under the terms negotiated beforehand in the contract. Upfront commitment reduces the risk of excessive dilution during the interim stage; this assumption is supported by several studies where investors compete for venture capital (e.g., Schwienbacher, 2013; de Bettignies \& Brander, 2007). Koskinen, Rebello, and Wang (2014) further argue that the allocation of bargaining power between a venture capitalist and entrepreneur varies, is independent of their private information, and is determined by the relative scarcity of venture financing. Ibrahim (2008) shows that angels generally do not exercise their bargaining power over entrepreneurs so as to help build a close relationship and earn favorable contract terms. van Osnabrugge and Robinson (2000) also contend that "even experienced angels do not achieve all the stringent venture capitalist terms. They do not have the negotiating power of venture capitalists..." (p. 37).

Hence, denoting the total cash infusion amount by $k$ (see Table 1, which summarizes all notations), we characterize the entrepreneur's ownership share $s$ and investment allocation between $k_{1}$ and $k_{2}\left(=k-k_{1}\right)$, which maximizes the entrepreneur's expected payoffs (as a share of venture value). We use an approach common in sequential decision making (backward induction) and provide all technical details in Appendix A, as we focus here on the rationale behind the key features of our formal framework. The investor imposes a continuation constraint on the entrepreneur, whereby the investor will terminate the contract if his or her payoffs do not cover the portion of investment deferred to stage 2. This constraint translates into a lower bound $\bar{L}_{1}$ for the investor's level of know-how at stage 1 , above which the investor should maintain the investment commitment into stage 2 because the investor's payoff is sufficiently high. In effect, the realized value of the venture does not justify further investment below $\bar{L}_{1}$. The investor also faces a deal-participation constraint, since the expected payoff must be sufficient to stimulate the investor to invest the total contracted amount in the new business prospect. Under this second constraint, the investor maintains the contract as long as the total cash investment $(k)$ is covered by his or her portion of value created.

These features (formally presented in Appendix A, Eq. A2), along with the proposed value function $V\left(p, L_{1}, L_{2}\right)$ described above, are consistent with the stewardship perspective for two primary reasons. First, creating more value from the venture can result in a smaller ownership share for either party (with a larger share for the other party) because each party's payoff will increase as the size of the pie increases. What enlarges that pie and the entrepreneur's payoff (formally in Appendix A, Eq. A2a) is the investor's know-how, which the investor constrains to be large enough for the first stage through the continuation constraint (formally in Appendix 
Table I. Notation Summary.

\begin{tabular}{|c|c|c|}
\hline \multicolumn{2}{|c|}{ Decision variables } & Parameters (non-deal-specific) \\
\hline$s$ & Entrepreneur's ownership share & Investor's output elasticity in stage I \\
\hline$k_{1}$ & Investment at development stage I & Investor's output elasticity in stage 2 \\
\hline$k_{2}$ & Investment at growth stage 2 & \\
\hline \multicolumn{3}{|c|}{ (or their optimal values if accompanied by $*$ ) } \\
\hline \multicolumn{3}{|c|}{ Random variables and their characteristics } \\
\hline$L_{1}$ & \multicolumn{2}{|c|}{ Investor's level of know-how in stage I, uniformly distributed on $[0, \mu]$} \\
\hline$\mu / 2$ & \multicolumn{2}{|c|}{ Mean of investor's level of know-how in stage I } \\
\hline$L_{2}$ & \multicolumn{2}{|c|}{ Investor's level of know-how in stage 2 , uniformly distributed on $[0, v]$} \\
\hline$v / 2$ & \multicolumn{2}{|c|}{ Mean of investor's level of know-how in stage 2} \\
\hline \multicolumn{3}{|c|}{ Other variables } \\
\hline$p$ & \multicolumn{2}{|l|}{ Productivity factor } \\
\hline k & \multicolumn{2}{|c|}{ Total investment amount, with $k=k_{1}+k_{2}$} \\
\hline$K_{L B}$ & \multicolumn{2}{|c|}{ Lower bound on total investment amount } \\
\hline$K_{U B}$ & \multicolumn{2}{|c|}{ Upper bound on total investment amount } \\
\hline $\bar{L}_{1}$ & \multicolumn{2}{|c|}{ Lower bound on investor's level of know-how in stage I } \\
\hline
\end{tabular}

A, Eq. A1). This enlargement of the valuation pie also rewards the investor for bringing more know-how, even if it increases ownership shares for the entrepreneur to maximize his or her expected payoff (and thus decreases the investor's shares). Second, the deal-participation constraint (formally in Appendix A, Eq. A2b) preserves the investor's economic interests and willingness to collaborate by minimizing losses if the lower bound $\bar{L}_{1}$ for know-how is not achieved during the first stage. It also preserves the entrepreneur's economic interests by ensuring that participation is a function of the investor's infusion of cash and know-how.

\section{Hypothesis Development}

Our analysis of the formal framework described above (detailed in Appendix A) enables us to characterize the impact of the total investment amount $k$ on the contractual terms (specifically, $s^{*}$ and $k_{2}^{*}$, with $k_{1}^{*}=k-k_{2}^{*}$ ) and to set deal-specific bounds on this investment amount within which know-how-based contracts are relevant from the stewardship perspective. In addition to strengthening our theoretical basis for empirical analysis, these formalities enable us to rationalize the findings that are not so intuitive by going beyond the stewardship perspective and bringing in explicit constraints (for continuation and for deal-participation) that ensure an alignment between the entrepreneur's and investor's interests. Moreover, the sensitivity of ownership sharing $\left(s^{*}\right)$ with respect to cash injection and know-how (formally derived in Appendix B) can be empirically tested to validate the characteristics of our contractual model.

Hypothesis 1: Two deal-specific critical bounds, $K_{L B}$ and $K_{U B}$, exist for any given investment deal, such that if the total investment amount is:

a. above the critical upper bound $\left(k>K_{U B}\right)$, no contract should be signed and the entrepreneur holds full ownership $\left(s^{*}=1\right)$; 


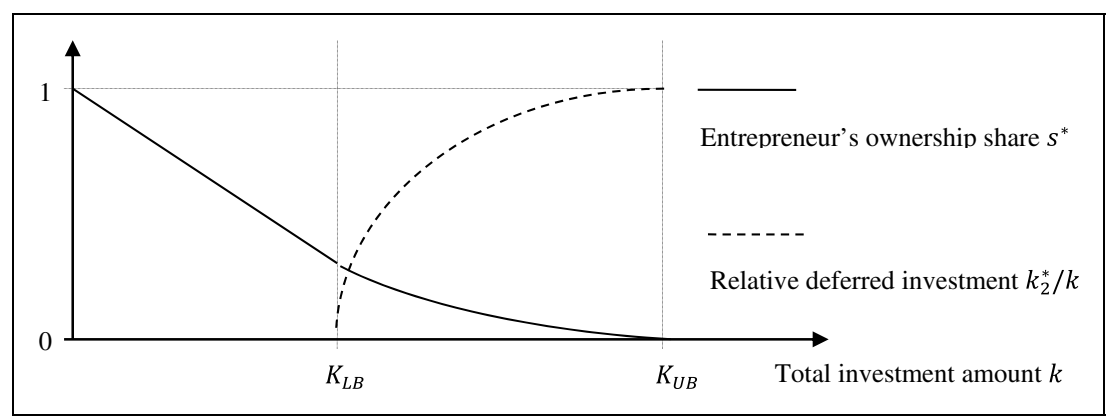

Figure I. Optimal ownership share for the entrepreneur and (relative) deferred investment.

b. below or equal to the critical lower bound $\left(k \leq K_{L B}\right)$, a contract in which the entrepreneur holds partial ownership $\left(s^{*}<1\right)$ with no investment deferral $\left(k_{2}^{*}=0\right)$ should be signed;

c. between these two bounds $\left(K_{L B}<k \leq K_{U B}\right)$, a contract in which the entrepreneur holds partial ownership $\left(s^{*}<1\right)$ with investment deferral $\left(k_{2}^{*}>0\right)$ should be signed.

The mathematical expressions for the deal-specific bounds $K_{L B}$ and $K_{U B}$ are developed in Appendix A, while their calculations are detailed later when we test H1 (Hypothesis 1). In Figure 1, we further estimate in $\mathbf{H 1}$ (specifically within its formal proof in Appendix A) that the entrepreneur's share will be smaller in H1(c) (where $K_{L B}<k \leq K_{U B}$ ) than in H1(b) (where $0<k \leq K_{L B}$ ). That is, with the entrepreneur requiring a larger total investment (in H1c), more of that investment should be deferred to stage 2 (growth). We also observe in Figure 1 that the deferred investment in its absolute or relative term increases as the entrepreneur requires a larger total investment (as proven in Appendix B). This greater deferred investment allows the investor to balance the risk created by granting the entrepreneur a larger amount of capital $k$.

We now posit a series of relationships between ownership sharing $\left(s^{*}\right)$, investor knowhow (at both stages), and cash injection by adding mathematical specifications to the optimal contract's qualitative characteristics in H1. The development of these relationships is consistent with the stewardship view from the entrepreneur's perspective with the investor's economic interests tied to the continuation and deal-participation constraints. Since no investment takes place in H1(a), we focus on H1(b) and H1(c). When the required investment is below a critical bound $\left(k \leq K_{L B}\right), \mathbf{H 1}(\mathrm{b})$ proposes a nonzero optimal ownership share for the entrepreneur but no deferred investment. When the investment is between two critical bounds $\left(K_{L B}<k \leq K_{U B}\right)$, H1(c) proposes a nonzero share and some deferred investment. What is significant is that, regardless of whether the required investment is below a critical bound or between two critical bounds, the formal representations of the entrepreneur's ownership share $s^{*}$ (detailed in Appendix A) lead to the same hypothesized relationships between the entrepreneur's ownership share and the investor's know-how and amount of cash injection. We provide formal details on this sensitivity analysis in Appendix B and concentrate next on offering rationales as we present testable hypotheses on these relationships.

In the relationship between the entrepreneur's ownership share and total amount of cash infused by the investor (depicted in Figure 1), as the entrepreneur seeks more cash infusion $(k)$, his or her ownership share decreases. This relationship finds broad support in the 
financial economics literature (e.g., Dahiya \& Ray, 2012) and leads to our second hypothesis:

Hypothesis 2: The entrepreneur's ownership share is negatively associated with the total investment amount.

We also posit two direct relationships based on consideration of the venture's value $(V)$ in addition to the two constraints (continuation and deal-participation) faced by the investor. We first argue that, as the investor's expected level of delivered know-how increases, either at stage $1(\mu)$ or at stage $2(v)$, so does the size of the pie's value $(V)$, while the amount of cash to be deferred decreases because an investor with more know-how is expected to understand the risks and to defer a smaller amount of cash to stage 2, if deemed necessary. As a result, the investor's continuation constraint for stage 2 can be satisfied with a smaller ownership share due to a tradeoff between that share and the value created. Moreover, the increase in the pie's size, that is, the venture's overall value, accompanied by an unchanged total cash investment, fulfill the investor's deal-participation constraint with a smaller ownership share (for the same tradeoff-based reason). In other words, based on the growth-of-valuation concept that is central to the stewardship perspective, and subject to the constraints that ensure an alignment between the entrepreneur's and investor's interests, we postulate two direct, positive relationships in the following hypotheses:

Hypothesis 3: The entrepreneur's ownership share is positively associated with the investor's knowhow at stage 1 (the development stage).

Hypothesis 4: The entrepreneur's ownership share is positively associated with the investor's knowhow at stage 2 (the growth stage).

The next hypotheses propose a moderation effect from the investment size $(k)$ on the relationship between the entrepreneur's ownership share and the investor's know-how. We posit that a large equity committed by an investor (to the entrepreneur) whose know-how can create additional value at stage 1 (or stage 2 ) will become even larger when this investor commits more funding. The rationale is: Consistent with the stewardship theory, and as described in Figure 1, the deferred investment $\left(k_{2}\right)$ increases when more cash $(k)$ is infused in the investment prospect. By deferring more cash to stage 2 (though not as much to violate the investor's stage 2 continuation constraint), less cash $\left(k_{1}\right)$ can be allocated to stage 1 . While $k_{1}$ decreases, the increase in the firm's overall value (owing to increased investor know-how) is large enough to overcome the increase in the deferred cash $k_{2}$ (due to the investor's stage 2 continuation constraint). As a result, the investor's deal-participation constraint can be satisfied with a smaller ownership share. Thus, as the total investment size increases, so does the entrepreneur's ownership share. This leads to two moderation hypotheses from the stewardship perspective:

Hypothesis 5: An investment deal with a high investment amount corresponds to a stronger positive effect of the investor's know-how at stage 1 (the development stage) on the entrepreneur's ownership share, compared to an investment deal with a low investment amount (i.e., positive interaction).

Hypothesis 6: An investment deal with a high investment amount corresponds to a stronger positive effect of the investor's know-how at stage 2 (the growth stage) on the entrepreneur's ownership share, compared to an investment deal with a low investment amount (i.e., positive interaction). 


\section{Data and Method}

We draw upon the AIPP data from the Kauffman Foundation collected with support from the Angel Capital Education Foundation. Angel investors are particularly relevant to our study because, based on their know-how, their role is often different from that of other types of investors such as venture capitalists. Angels take on formal roles (e.g., they secure board seats and implement negative covenants) that give them power to approve major decisions (Ibrahim, 2008). This dataset includes angel investments in early-stage North American ventures between 1990 and 2007 (for details, see Wiltbank \& Boeker, 2007; Wiltbank, Read, Dew, \& Sarasvathy, 2009). It includes 285 completed surveys by angel investors, along with the amount of cash they originally invested in the venture plus any follow-on investment(s), the years of these investments, the year of discontinuation, and the amount of cash that the investor earned during the investment period and at exit. It also includes the number of self-reported hours of due diligence performed by the angels on each deal, the angels' industry and entrepreneurial expertise (in number of years), and frequency (i.e., daily vs. weekly) of their participation in the venture. We chose a subset of angels from the AIPP dataset for our study based on two main criteria. The angels (a) had met with the entrepreneurs after investment to help develop the venture and (b) had gathered information on the entrepreneur's managerial, technical, marketing and past start-up experiences. Of the AIPP's 285 deals, 85 $(30 \%)$ met our requirements and were included in our dataset. ${ }^{3}$

Our study follows that of Wiltbank et al. (2009) who described the AIPP data collection process (a survey) and how representativeness concerns were mitigated. They initiated and pilot-tested their survey after discussions with angels and used separate sources in data collection to reduce selection bias. To check for a possible self-selection bias whereby only successful investors would respond, they compared their data with other samples used in entrepreneurial investing and found no significant self-selection bias. The cutoff year also prevented bias from the 2008 economic crisis, which significantly dampened angel investment activities for several years following it.

\section{Dependent and Independent Variables}

Our dependent variable is ownership share, which is not directly reported in the AIPP data. We follow the conventional approach of dilution agreement based on total investment amount and pre-investment valuation (Neal, 2004). An investor's ownership share, $1-s$, equals his or her total investment (totalinvested) divided by the sum of pre-investment valuation (initrevs) and totalinvested (e.g., a pre-investment valuation of $\$ 2 \mathrm{M}$ plus a $\$ 1 \mathrm{M}$ total investment yield a post-investment valuation of $\$ 3 \mathrm{M}$ with the investor owning 33\%; Wiltbank $\&$ Boeker, 2007). We set a conservative proxy for pre-investment valuation by using initial revenues and ignore leverage, although we report on a robustness analysis showing that our key findings remain robust when we relax this assumption.

Our first independent variable is totalinvested. ${ }^{4}$ The second and third independent variables are the investor's level of know-how in stages 1 and 2. Since deal-specific know-how cannot be measured by direct observation (Guthrie, 2001), we follow the lead of Sapienza (1992) and Kelly and Hay (2003) to generate proxy averages $\mu$ and $v$ for their uncertain levels, $L_{1}$ and $L_{2}$, respectively, based on the angels' reported data on their experiences. To build these constructs that differentiate the investor's experience across two distinct stages (Janney \& Folta, 2006), we conducted factor analysis on four items reported in the AIPP data: the number of years the angel had been an entrepreneur (yearsentre), the number of firms the angel had founded (numfounded), years of the angel's work experience in an industry related to this venture 
(industryexp), and total number of angel investments that the angel had made to date (totalinv).

We include these variables (on the investor's years of experience and number of previous new venture involvements) in the operationalization of know-how because the competencebased perspective (as applied in, e.g., Colombo \& Grilli, 2005; Pahnke et al., 2015; Schwienbacher, 2013) suggests a positive link between a new venture's human capital and its post-entry performance (including valuation). Human capital comes from both the entrepreneur who initiates the investment prospect and the angel who chooses to invest, and is the basis for the know-how to be injected in the resulting new venture. The angel's human capital complements the entrepreneur's by providing knowledge and expertise that can inform product development (and advance the venture at the development stage) as well as growth-related issues (such as dealing with competitors at the growth stage) (Ibrahim, 2008). Colombo and Grilli (2005) argue that human capital in new firms can be generic, as in educational accomplishments through years of schooling and years of work experience establishing new firms. It can also be specific, as in business/managerial experience in a given industry and in prior self-employment. Specific human capital can also come from an investor's tenure as an executive (Pahnke et al., 2015) or time spent as an active investor (Schwienbacher, 2013). In other words, because the stock of human capital also builds from the investor's time in as well as number of previous new venture involvements (similarly shown to be crucial factors of entrepreneurial experience in Stuart \& Abetti, 1990), we choose to also consider the number of funded businesses and total number of investments made by the angel to date.

The factor analysis resulted in two specific formulas (and item selection) that we used to assess the two levels of deal-specific investor know-how, $\ln \mu$ and $\ln v$, for any given deal. We use logarithmic transformation here and in the regression analysis owing to the multiplicative form for ownership sharing $\left(s^{*}\right)$ (see Appendix A). We derived the coefficients in these formulas from the component-score coefficient matrix of the factor analysis (see Table 2), yielding the following two weighted equations:

$$
\begin{gathered}
\ln \mu=0.385 \ln \text { yearsentre }+0.343 \ln \text { numfounded and } \\
\ln v=0.703 \ln \text { industry } \exp +0.482 \ln \text { totalinv. }
\end{gathered}
$$

The first factor is a proxy for stage 1 know-how since it captures the investor's early-stage (know-how) work in his or her capacity as an entrepreneur. The second factor is a proxy for

Table 2. Component Score Coefficient Matrix.

\begin{tabular}{lcc}
\hline & Component \\
\cline { 2 - 3 } & 1 & 2 \\
\hline Total number of investments made by the angel (In totalinv) & .273 & .482 \\
Years of working experience the angel had in an industry related to the &. .099 & .703 \\
$\quad$ venture (In industryexp) & .385 & -.220 \\
Years the angel had been an entrepreneur (In yearsentre) & .343 \\
Number of firms the angel had founded (In numfounded) & .126 \\
Extraction Method: Principal Component Analysis; Rotation Method: Varimax with Kaiser Normalization
\end{tabular}


stage 2 know-how since it corresponds to the investor's experience in growing firms in related industry.

\section{Control Variables}

Our formal representation of the venture's value $V$ also allows us to control for the productivity factor $p$, which is a scaling measure that transforms expected values of investor know-how into anticipated venture valuation; thus we operationalize it as the entrepreneur's value-creation ability (van Praag \& Versloot, 2007). This factor is expected to positively impact the entrepreneur's ownership share as suggested by our formal framework (see Appendix B), which is supported by the financial contract literature (Burchardt et al., 2014). Angels have also been shown to assess an entrepreneur's ability using a variety of criteria (for a review, see Maxwell et al., 2011), including the entrepreneur's number of years of work experience in a relevant field (Wiltbank et al., 2009). However, value creation ability should be based on various factors, including the entrepreneur's experience in industry (Sudek, 2006), technology and marketing (Mason \& Stark, 2004; Eckhardt \& Shane, 2006), management, and teams, as well as positive team outcomes (Maxwell et al., 2011; Sudek, 2006).

We thus develop a proxy for this productivity factor based on six measures $(j \in[1,6])$ from the AIPP data that focus on the entrepreneur: (1) founded and led other firms; (2) led other new ventures that succeeded; (3) significant large-firm experience; (4) significant technical experience; (5) significant managerial experience; and (6) significant sales/marketing experience. In the AIPP data, the investor examines deal $i$ prior to making a funding decision, and assigns for every $j \in[1,6]$ a binary variable $p_{i j}=1$ if he or she identifies the $j^{\text {th }}$ abovementioned measures, with $p_{i j}=0$ otherwise. Based on these (deal-specific) binary variables, we use a pairwise index of similarity ${ }^{5}$ between each entrepreneur and a hypothetical fully able entrepreneur to determine the entrepreneur's value-creation ability. In other words, for any given deal $x$, we assess how close, experience-wise, that deal's entrepreneur is to an "ideal" entrepreneur. We thus calculate a similarity index $S_{x i}$ that captures the difference in experiences between deal $x$ 's entrepreneur and the "ideal" entrepreneur $i$ (for details of this index calculation see Appendix C). Since the interaction frequency between the two parties can speed up this productivity (Sapienza, 1992), we weigh the index of similarity by this frequency reported as interactions in the AIPP data. Formally, for deal $x$ we obtain $p=$ interactions $\times S_{x i}$.

Moreover, we consider a co-investor dummy and the industry of the investment prospect. The co-investor dummy equals " 0 " if the investment is from a single investor and " 1 " if it is from a syndicated investor group. Industry is based on the Standard Industrial Classification (SIC) code and its value is allocated as follows: $1=I T$ services, $2=$ electronics products, $3=$ health-care product services, $4=$ retail/distribution, $5=$ consumer products/services, $6=$ business products/services, and $0=$ others.

\section{Regression Models}

We use ordinary least squares regression models to test $\mathbf{H 2}$ to H6; we test $\mathbf{H 1}$ with straightforward $t$-tests, as described in the next section. We require three regression equations, where the entrepreneur's ownership share is the dependent variable. The independent variables are the total investment amount $(k)$, plus the investor's expected levels of know-how at stages 1 and 2 ( $\mu$ and $\nu$, respectively), as proposed by the mathematical expression for this ownership share ( $s^{*}$ derived in Appendix A). For each deal $i$, we apply logarithmic transformations ${ }^{6}$ to the dependent and independent variables, and to the productivity-factor control owing to the multiplicative form for $s^{*}$ (shown in Appendix A). We then add the co-investor and industry 
Table 3. Correlation Matrix and Descriptive Statistics.

\begin{tabular}{|c|c|c|c|c|c|c|c|c|c|c|c|}
\hline \multicolumn{2}{|c|}{ Variable } & \multirow{2}{*}{$\begin{array}{c}\text { Mean } \\
-0.24\end{array}$} & \multirow{2}{*}{$\frac{S D}{0.40}$} & \multirow{2}{*}{$\frac{1}{1.00}$} & \multirow[t]{2}{*}{2} & \multirow[t]{2}{*}{3} & \multirow[t]{2}{*}{4} & \multirow[t]{2}{*}{5} & \multirow[t]{2}{*}{6} & \multirow[t]{2}{*}{7} & \multirow[t]{2}{*}{ VIF } \\
\hline 1 & $\begin{array}{l}\text { Entrepreneur's ownership } \\
\text { share (In s) }\end{array}$ & & & & & & & & & & \\
\hline 2 & $\begin{array}{l}\text { Investor's know-how at } \\
\text { stage I }(\ln \mu)\end{array}$ & 1.37 & 0.47 & -0.06 & 1.00 & & & & & & 1.08 \\
\hline 3 & $\begin{array}{l}\text { Investor's know-how at } \\
\text { stage } 2(\ln v)\end{array}$ & -3.61 & 5.60 & 0.14 & $0.25^{*}$ & 1.00 & & & & & 1.15 \\
\hline 4 & Total investment amount $(\ln k)$ & 10.92 & 1.21 & $-0.7^{* * * *}$ & 0.04 & -0.06 & 1.00 & & & & 1.06 \\
\hline 5 & Productivity factor $(\ln p)$ & 0.29 & 0.75 & 0.07 & 0.11 & 0.17 & 0.11 & 1.00 & & & 1.08 \\
\hline 6 & Co-investor dummy & 3.04 & 4.53 & 0.18 & -0.02 & -0.20 & -0.16 & -0.08 & 1.00 & & 1.08 \\
\hline 7 & Industry & 2.47 & 2.05 & -0.03 & 0.03 & -0.07 & -0.06 & -0.19 & 0.09 & 1.00 & 1.05 \\
\hline
\end{tabular}

Note. VIF $=$ variance inflation factor.

$* p<.10 . * * p<.05$. **** $p<.01 \quad(n=85)$

controls, along with an error term $\left(e_{i}\right)$. We also include two interaction terms $-\ln \mu \times \ln k$ and $\ln v \times \ln k$ - to test the moderation effect from the total investment amount on the relationship between the entrepreneur's ownership share and investor's know-how (at both stages) posited in $\mathbf{H 5}$ and $\mathbf{H 6}$. Testing $\mathrm{H2}$ to $\mathrm{H6}$ thus requires

$$
\begin{aligned}
& \text { Model } 1: \ln s_{i}=\beta_{0}+\beta_{1} \ln k_{i}+\beta_{6} \ln p_{i}+\beta_{7} \text { coinvestor }_{i}+\beta_{8} \text { industry }_{i}+e_{1 i} \text {, } \\
& \text { Model 2: } \ln s_{i}=\beta_{0}^{\prime}+\beta_{1}^{\prime} \ln k_{i}+\beta_{2}^{\prime} \ln \mu_{i}+\beta_{3}^{\prime} \ln _{i}+\beta_{6}^{\prime} \ln p_{i}+\beta_{7}^{\prime} \text { coinvestor }_{i} \\
& +\beta_{8}^{\prime} \text { industry }_{i}+e_{2 i} \\
& \text { Model } 3: \ln s_{i}=\beta_{0}^{\prime \prime}+\beta_{1}^{\prime \prime} \ln k_{i}+\beta_{2}^{\prime \prime} \ln \mu_{i}+\beta_{3}^{\prime \prime} \ln _{i}+\beta_{4}^{\prime \prime} \ln k_{i} \times \ln \mu_{i}+\beta_{5}^{\prime \prime} \ln k_{i} \times \ln _{i} \\
& +\beta_{6}^{\prime \prime} \ln p_{i}+\beta_{7}^{\prime \prime} \text { coinvestor }_{i}+\beta_{8}^{\prime \prime} \text { industry }_{i}+e_{3 i}
\end{aligned}
$$

Table 3 summarizes the correlations with all variance inflation factors below 2, which eliminates multicollinearity concerns. The Shapiro-Wilk statistics raises no concerns for normality nor does the Koenker-Bassett test for homogeneity of variance.

\section{Model Validation and Hypothesis Testing}

Of the 85 deals that met our requirements, 58 had upfront financing from the angels (as no deferred investment was reported), while the remaining 27 had financing beyond the first stage. ${ }^{7}$ We first used the insights from $\mathbf{H} \mathbf{1}$ to rationalize this difference in the two types of financing since it suggests two bounds, $K_{L B}$ and $K_{U B}$, on the total investment amount $k$, which helps determine when financing should be upfront or when it should be staged. Specifically, these deal-specific bounds are formally derived from the optimization problem (detailed in Appendix A, Eqs. A2a-A2c): $K_{L B} \equiv \frac{p \mu^{a} v^{b}}{[a+1]^{2}[b+1]}$ and $K_{U B} \equiv \frac{p \mu^{a} v^{b}}{[b+1]}$. For each deal, we evaluate the control variable $p$ and the independent variables $\mu$ and $v$ from the proxies described earlier. The nondeal-specific values for $a$ and $b$ are assigned the regression coefficients of $\ln \mu$ and $\ln v$ in Model 3 (above) and specified in Table 4, which summarizes the regression results. ${ }^{8}$ For each deal, we then computed the specific bounds $K_{L B}$ and $K_{U B}$ and assessed whether the deal should have received the full investment amount upfront (when $K_{L B}<k \leq K_{U B}$ ) or should have been divided into two amounts (when $k \leq K_{L B}$ ) based on the reported total investment amount $k$. 


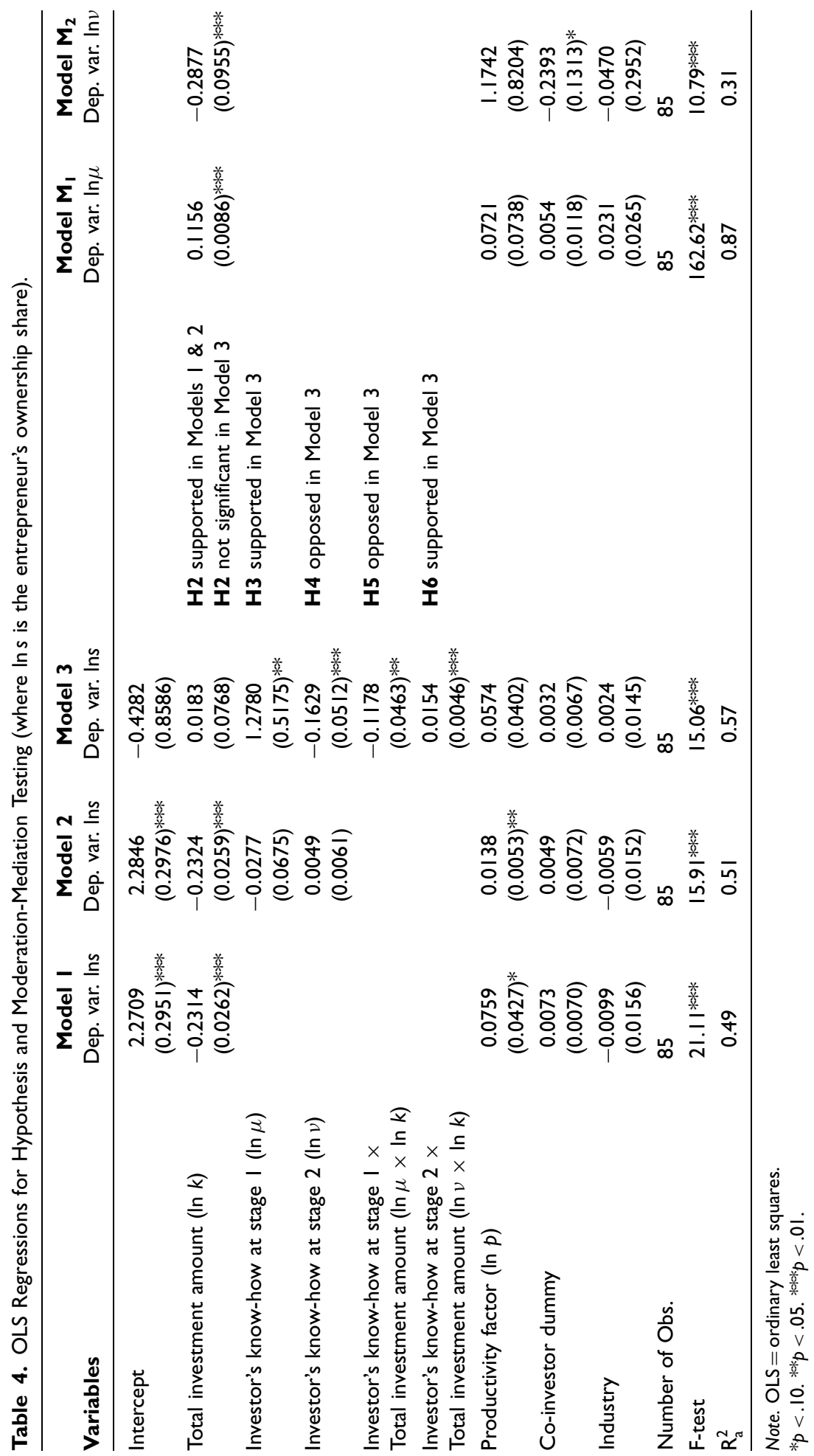


For the subsample with upfront financing, we constructed a measure $\left(\ln k-\ln K_{L B}\right)$ that was positive for 55 of the 58 deals that received the entire investment amount upfront and thus also qualified for that specific type of financing as prescribed by the bounds. Based on a pairwise $t$-test, the average value of this measure was positive $(p<.05)$. Similarly, we constructed a measure $\left(\ln K_{U B}-\ln k\right)$ that was positive in 84 out of 85 deals, and in a pairwise $t$ test the average value of this measure was also positive $(p<.05)$. In other words, the mean value of $\ln k$ was within our two computed deal-specific bounds. In addition to providing support for H1, these findings support the existence of (deal-specific) lower and upper bounds on the investment size, which serve as robust indicators of whether a deal should receive upfront financing, or if the funding should be distributed over two stages.

Moving on to testing the remaining hypotheses, Model 1 in Table 4 focuses on the total investment amount to test $\mathbf{H 2}$, while Model 2 also incorporates the investor's know-how at stages 1 and 2. Model 1 and Model 2 support the negative relationship between the total investment amount and the entrepreneur's ownership share postulated in $\mathbf{H 2}$. We also observe in Model 2 that the regression coefficient associated with the investor's know-how at either stage is not significant. However, incorporating stage 1 and stage 2 know-how, along with their interactions with the investment size, in Model 3 alters these findings and increases the adjusted $R^{2}$ in Table 4 from .51 (in Model 2) to .57 (in Model 3). We therefore use Model 3 to examine $\mathbf{H 2}$ to H6. We observe that the regression coefficient associated with the total investment amount changes in value and sign, and loses its significance (from $-0.2324, p<.01$ to $0.0183, p>.10$ ) owing to interaction effects. Thus, $\mathbf{H 2}$ is no longer supported, since the investment size affects the entrepreneur's ownership share through its interaction with the estimated level of the investor's know-how (at both stages).

We next summarize the findings on direct and indirect (i.e., interaction) effects linked to the investor's know-how. Model 3 indicates support for $\mathbf{H 3}$ by showing a significant positive association between the entrepreneur's ownership share and the investor's know-how at stage $1(p<.05)$. However, Model 3 rejects $\mathbf{H 4}$, by showing a significant negative association between the entrepreneur's ownership share and the investor's know-how at stage $2(p<.01)$. The postulated moderating effect of the investment size on the relationship between the entrepreneur's ownership share and the investor's know-how at stage 1 is negative and significant $(p<.05)$, thus rejecting H5. Conversely, the postulated moderating effect at stage 2 is positive and significant $(p<.01)$, thus supporting $\mathbf{H 6}$.

Given that the investment size is significant as a direct effect in Model 1 and Model 2 but is not significant in Model 3 (i.e., when we examine interactions), we proceeded with a mediation check. We thus refined the moderation effect in $\mathbf{H 5}$ and $\mathbf{H 6}$ by considering a moderated mediation effect from the total investment amount on the relationship between the entrepreneur's ownership share and the investor's know-how (at both stages). Following the prescription set by Baron and Kenny (1986) and Dawson (2014), we must examine the relationship between the investor's know-how and the total investment amount (i.e., a mediation effect). Thus we consider:

$$
\begin{aligned}
& \text { Model } \mathrm{M}_{1}: \ln \mu_{i}=\delta_{1} \ln k_{i}+\delta_{2} \ln p_{i}+\delta_{3} \text { coinvestor }_{i}+\delta_{4} \text { industry }_{i}+e_{M_{1} i} \quad \text { and } \\
& \text { Model } \mathrm{M}_{2}: \ln _{i}=\delta_{1}^{\prime} \ln k_{i}+\delta_{2}^{\prime} \ln p_{i}+\delta_{3}^{\prime} \text { coinvestor }_{i}+\delta_{4}^{\prime} \text { industry }_{i}+e_{M_{2} i} .
\end{aligned}
$$

As shown in Table 4, the investor's know-how mediation effect is created through the total investment amount ( $\ln k$ ) since in Models $\mathrm{M}_{1}$ and $\mathbf{M}_{2}$ both regression coefficients are significant $(p<.01)$ and in Model 3 the regression coefficients for investor know-how (at both 
stages) are significant while the coefficient for the total investment amount is not significant. We can thus report a moderated mediation effect, since both interaction coefficients in Model 3 are significant. However, because the interaction coefficient is positive only for stage 2, we again conclude that $\mathbf{H 6}$ is supported but $\mathbf{H 5}$ is rejected. ${ }^{9}$

Consistent with the stipulation from Hayes and Scharkow (2013) as a follow-on test to separate the direct and indirect effects originally proposed by Baron and Kenny's (1986) prescription, we also add support to the disaggregated effects of the interactions between investment size and investor know-how levels by running a bootstrap analysis. We report the results of this bootstrap analysis as confidence intervals for relevant estimates of four regression coefficients in our specification of Model 3. Specifically, the null hypotheses stipulate that the corresponding regression coefficient equals 0 . The $95 \%$ confidence intervals are $[0.6346,2.0390]$ for $\beta_{2}^{\prime \prime}$ used to test H3, $[-0.3119,-0.0050]$ for $\beta_{3}^{\prime \prime}$ used to test $\mathbf{H 4}$, $[-0.1803,-0.0585]$ for $\beta_{4}^{\prime \prime}$ used to test H5, and [0.0001, 0.0284] for $\beta_{5}^{\prime \prime}$ used to test $\mathbf{H 6}$. Since none of these intervals contains 0 , we reject the null hypotheses and conclude that this analysis supports the reported results associated with $\mathbf{H 3}$ to $\mathbf{H 6}$.

Regarding the control variables, the positive sign of the regression coefficients for the productivity factor is consistent with our prediction, even though it is only significant in Model 1 (weakly with $p<.10)$ and Model $2(p<.05)$. This suggests that the entrepreneur and angel generally did not consider this factor, which we substituted for the entrepreneur's value-creation ability as a control when writing these contracts. Similarly, the co-investor dummy is weakly significant and negative in model $\mathbf{M}_{2}$, suggesting that the presence of co-investors tends to reduce the association between the investment size and investor knowhow at stage 2 (growth).

Moreover, since the proxy for pre-investment valuation is not reported in the AIPP dataset, we conservatively assumed a multiple of 1 (i.e., no leverage) on initial revenues to proxy pre-investment valuation. However, this could be viewed as a naïve approach, which encouraged us to further explore the robustness of our key findings by considering different industry multiples/leverages based on publicly available valuation data (Dahl, 2010). The base case shown in Table 5, column C1 replicates Model 1 (the main significant effects only) and Model 3 (with interaction effects) in Table 4. While the implicit leverage is 1 in the base case, it ranges from 5 to 30 depending on the industry in Table 5, column $\mathrm{C} 2$, where we use this leverage to compute a revised pre-investment valuation needed to determine our dependent variable (i.e., the logarithmic transformation of the entrepreneur's ownership share, $\ln s$ ). As shown in column $\mathrm{C} 2$, all key regression results (i.e., sign and significance of key independent variables) still hold with only the following caveat: due to variation created by the leverage factor that is built into the dependent variable (and varies across industries), the industry control becomes significant in Model 1 , while the total investment amount $(\ln k)$ becomes significant in Model 3.

As an additional robustness check, we dig deeper into the impact of deal type (i.e., upfront funding with $k_{2}=0$ and staged funding with $k_{2}>0$ ) and add a control variable (deal-type dummy), which takes the value " 1 " if the deal's total investment is made up front and " 0 " if the investment is distributed in stages. Column $\mathrm{C} 3$ shows that although this control variable is not significant, our main findings remain robust to this change. Moreover, to address potential drawbacks associated with data coverage in terms of years, which end in 2007, we investigated the robustness of our findings by considering the recession period from 2000 to 2003. We added a control variable (early-year dummy), which takes the value " 1 " if the deal occurred prior to 2000 and " 0 " otherwise. Table 5, column C4 shows that all key results still hold, while this added control variable is not significant. That is, our key findings remain robust to this segmentation. 
Table 5. Robustness Analysis (where the dependent variable is the entrepreneur's ownership share, Ins).

\begin{tabular}{|c|c|c|c|c|}
\hline Variables & $\mathrm{Cl}$ : base & $\begin{array}{l}\text { C2: with } \\
\text { leverage }\end{array}$ & $\begin{array}{l}\text { C3: with } \\
\text { deal-type } \\
\text { dummy }\end{array}$ & $\begin{array}{l}\text { C4: with } \\
\text { early-year } \\
\text { dummy }\end{array}$ \\
\hline & \multicolumn{4}{|c|}{ Model I } \\
\hline Intercept & $\begin{array}{l}2.2709 \\
(0.2951)^{* * * *}\end{array}$ & $\begin{array}{l}\text { I.1254 } \\
(0.1596)^{* * *}\end{array}$ & $\begin{array}{l}2.1585 \\
(0.3301)^{* * * *}\end{array}$ & $\begin{array}{l}2.2622 \\
(0.3009)^{* * *}\end{array}$ \\
\hline Total investment amount (ln k) & $\begin{array}{l}-0.2314 \\
(0.0262)^{* * *}\end{array}$ & $\begin{array}{l}-0.1084 \\
(0.0142)^{* * *}\end{array}$ & $\begin{array}{l}-0.2193 \\
(0.0307)^{* * *}\end{array}$ & $\begin{array}{l}-0.2300 \\
(0.0275)^{* * *}\end{array}$ \\
\hline Productivity factor $(\ln p)$ & $\begin{array}{l}0.0759 \\
(0.0427)^{*}\end{array}$ & $\begin{array}{l}0.0428 \\
(0.0231)^{*}\end{array}$ & $\begin{array}{l}0.0731 \\
(0.0430)^{*}\end{array}$ & $\begin{array}{l}0.0772 \\
(0.0437)^{*}\end{array}$ \\
\hline Co-investor dummy & $\begin{array}{c}0.0073 \\
(0.0070)\end{array}$ & $\begin{array}{c}0.0035 \\
(0.0038)\end{array}$ & $\begin{array}{c}0.0078 \\
(0.0070)\end{array}$ & $\begin{array}{c}0.0071 \\
(0.0072)\end{array}$ \\
\hline Industry & $\begin{array}{c}-0.0099 \\
(0.0156)\end{array}$ & $\begin{array}{l}-0.0175 \\
(0.0084)^{* *}\end{array}$ & $\begin{array}{r}-0.0106 \\
(0.0156)\end{array}$ & $\begin{array}{c}-0.0101 \\
(0.0157)\end{array}$ \\
\hline Deal-type dummy & & & $\begin{array}{r}-0.0598 \\
(0.0780)\end{array}$ & \\
\hline Early-year dummy & & & & $\begin{array}{c}-0.0122 \\
(0.0687)\end{array}$ \\
\hline Number of obs. & 85 & 85 & 85 & 85 \\
\hline F-test & $21.11 * * *$ & $16.92 * * *$ & $16.91 * * *$ & $16.68 * * *$ \\
\hline \multirow[t]{2}{*}{$\mathrm{R}_{\mathrm{a}}^{2}$} & 0.49 & 0.43 & 0.49 & 0.48 \\
\hline & \multicolumn{4}{|c|}{ Model 3} \\
\hline Intercept & $\begin{array}{r}-0.4282 \\
(0.8586)\end{array}$ & $\begin{array}{l}-0.8658 \\
(0.2646)^{* * *}\end{array}$ & $\begin{array}{r}-0.5208 \\
(0.8745)\end{array}$ & $\begin{array}{c}-0.3914 \\
(0.8631)\end{array}$ \\
\hline Total investment amount (ln k) & $\begin{array}{c}0.0183 \\
(0.0768)\end{array}$ & $\begin{array}{l}0.0805 \\
(0.0237)^{* * *}\end{array}$ & $\begin{array}{c}0.0280 \\
(0.0786)\end{array}$ & $\begin{array}{c}0.0131 \\
(0.0774)\end{array}$ \\
\hline Investor's know-how at stage I $(\ln \mu)$ & $\begin{array}{l}1.2780 \\
(0.5175)^{* *}\end{array}$ & $\begin{array}{l}0.8752 \\
(0.1595)^{* * *}\end{array}$ & $\begin{array}{l}1.2848 \\
(0.5197)^{* *}\end{array}$ & $\begin{array}{l}1.2476 \\
(0.5211)^{* *}\end{array}$ \\
\hline Investor's know-how at stage $2(\ln v)$ & $\begin{array}{l}-0.1629 \\
(0.0512)^{* * *}\end{array}$ & $\begin{array}{l}-0.0529 \\
(0.0158)^{* * *}\end{array}$ & $\begin{array}{l}-0.1632 \\
(0.0514)^{* * * *}\end{array}$ & $\begin{array}{l}-0.1707 \\
(0.0526)^{* * *}\end{array}$ \\
\hline $\begin{array}{l}\text { Investor's know-how at stage I } \times \\
\text { Total investment amount }(\ln \mu \times \ln k)\end{array}$ & $\begin{array}{l}-0.1178 \\
(0.0463)^{* *}\end{array}$ & $\begin{array}{l}-0.0830 \\
(0.0143)^{* * *}\end{array}$ & $\begin{array}{l}-0.1184 \\
(0.0465)^{* *}\end{array}$ & $\begin{array}{l}-0.1151 \\
(0.0467)^{* * *}\end{array}$ \\
\hline $\begin{array}{l}\text { Investor's know-how at stage } 2 \times \\
\text { Total investment amount }(\ln v \times \ln k)\end{array}$ & $\begin{array}{l}0.0154 \\
(0.0046)^{* * * *}\end{array}$ & $\begin{array}{l}0.0050 \\
(0.0014)^{* * * *}\end{array}$ & $\begin{array}{l}0.0154 \\
(0.0047)^{* * *}\end{array}$ & $\begin{array}{l}0.0162 \\
(0.0048)^{* * *}\end{array}$ \\
\hline Productivity factor $(\ln p)$ & $\begin{array}{c}0.0574 \\
(0.0402)\end{array}$ & $\begin{array}{c}0.0194 \\
(0.0124)\end{array}$ & $\begin{array}{c}0.0558 \\
(0.0404)\end{array}$ & $\begin{array}{c}0.0519 \\
(0.0411)\end{array}$ \\
\hline Co-investor dummy & $\begin{array}{c}0.0032 \\
(0.0067)\end{array}$ & $\begin{array}{c}0.0001 \\
(0.0021)\end{array}$ & $\begin{array}{l}0.0035 \\
(0.0068)\end{array}$ & $\begin{array}{c}0.0042 \\
(0.0069)\end{array}$ \\
\hline Industry & $\begin{array}{l}0.0024 \\
(0.0145)\end{array}$ & $\begin{array}{r}-0.0047 \\
(0.0045)\end{array}$ & $\begin{array}{l}0.0019 \\
(0.0146)\end{array}$ & $\begin{array}{l}0.0034 \\
(0.0146)\end{array}$ \\
\hline Deal-type dummy & & & $\begin{array}{r}-0.0456 \\
(0.0724)\end{array}$ & \\
\hline Early-year dummy & & & & $\begin{array}{c}0.046 I \\
(0.066 I)\end{array}$ \\
\hline Number of obs. & 85 & 85 & 85 & 85 \\
\hline F-test & $15.06 * * *$ & $18.98 * * *$ & $13.32 * * *$ & $13.35 * * *$ \\
\hline $\mathrm{R}_{\mathrm{a}}^{2}$ & 0.57 & 0.63 & 0.57 & 0.57 \\
\hline
\end{tabular}

Note. $*_{p}<.10 . * * p<.05 . * * * p<.01$. 


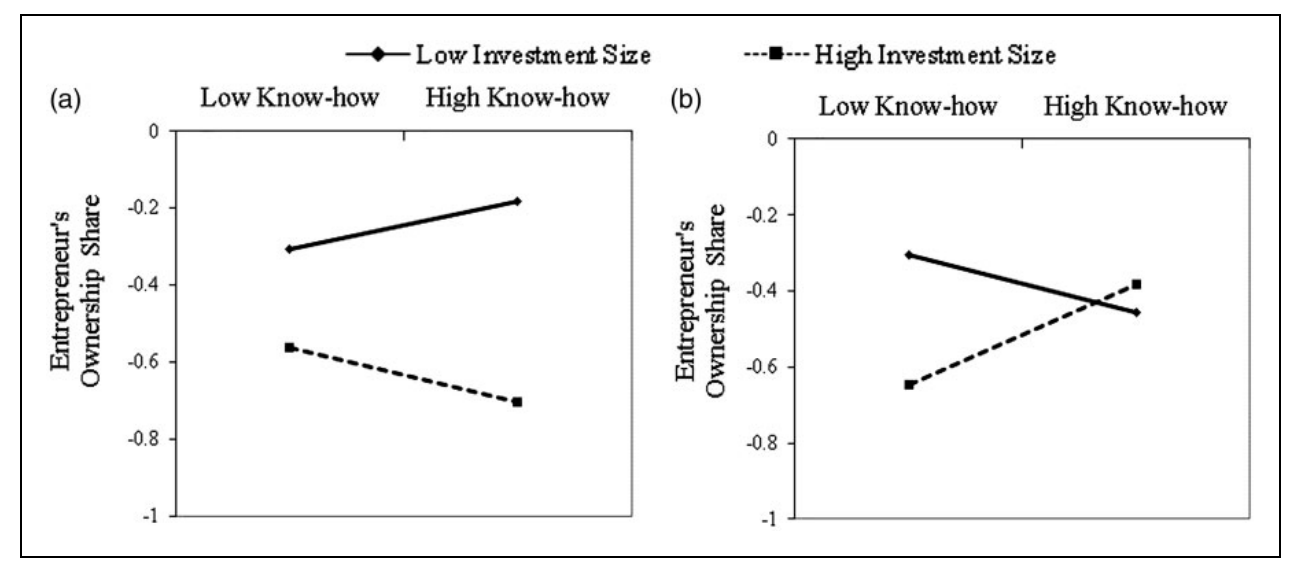

Figure 2. Interaction between investment size and expected know-how levels.

\section{Discussion}

We have shown that during either the development stage 1 or growth stage 2 , the impact of both the total investment amount and the investor's know-how in contracts prompts ownership-sharing tradeoffs for know-how and financial capital. We discuss these tradeoffs based on Figure 2, where, consistent with our empirical analysis, a logarithmic transformation is used on all relevant variables (i.e., investor know-how, investment size, and entrepreneur's ownership share). To depict the disaggregated effects of the interactions, we set up labels - low versus high - that denote the levels of know-how $(\ln \mu$ and $\ln v$ for stage 1 and stage 2 , respectively) and investment size $(\ln k)$, one standard deviation below and above their respective means. We compute the entrepreneur's ownership share for low versus high investment sizes, and low versus high levels of investor know-how, based on Model 3 in Table 4.

Figure 2(a) shows that for (log-transformed) low investment sizes, the (log-transformed) entrepreneur's ownership share along the Y-axis moves from -0.34 to -0.21 when the (logtransformed) investor's level of know-how moves from low to high. For higher investment sizes, the movement in shares goes from -0.59 to -0.74 . Hence, when the investor's level of know-how is low in stage 1, raising the scaled investment size from a standard deviation below the mean to a standard deviation above the mean leads to $22.6 \%$ reduction in the entrepreneur's ownership share (i.e., absolute, non-log transformed shares). Likewise, when the investor's level of know-how is high in stage 1, raising the scaled investment size to a standard deviation above the mean from a standard deviation below the mean creates an even steeper reduction in the entrepreneur's ownership shares, a $40.8 \%$ reduction in shares. Simultaneously increasing the investor's know-how and cash infusion therefore results in diverging effects on the entrepreneur's ownership share in stage 1. This is illustrated in Figure 2(a): the gap between the upper and lower curves widens as investment size increases.

Moreover, in Model 3 in Table 4, the interaction between the total investment amount $(\ln k)$ and investor know-how in stage $1(\ln \mu)$ has a reverse (and significant) effect (compared to the direct effect of investor know-how) on the entrepreneur's ownership share. That is, if the investor contributes a high level of know-how in stage 1 (i.e., the scaled level of knowhow goes from a standard deviation below the mean to a standard deviation above the mean), 
then based on our data, the investment size increases by $22.0 \%$ on average, and, in turn, the investor's ownership share increases by $33.4 \%$ (while a mere $1 \%$ increase in investment would yield just a $1.5 \%$ rise in that ownership share).

Figure 2(b) tells a different story for growth stage 2. For low-investment sizes, the entrepreneur's ownership share (along the Y-axis) moves from -0.32 to -0.67 when the investor's level of know-how moves from low to high. For higher investment sizes, the movement in shares goes from -0.48 to -0.40 . That is, when the investor's know-how level is low in stage 2 , increasing the scaled investment size from a standard deviation below the mean to a standard deviation above the mean, results in a $29.5 \%$ reduction in the entrepreneur's ownership share (i.e., absolute, non-log transformed). When the investor's level of know-how is high in stage 2 , this leads to a $7.8 \%$ increase in the entrepreneur's ownership share. In other words, as Figure 2(b) illustrates, the gap between the upper and lower curves first narrows, and then widens with increases in investment size, thus increasing the gap, indicating a loss in the entrepreneur's ownership share.

We have carried out the formalization of contracts based on the stewardship perspective (e.g., Davis et al., 1997) and developed our hypotheses from the entrepreneur's perspective with the investor's economic interest tied to the deal-participation and continuation (stage 1 to 2) constraints. Thus, in our formulation, the interests of entrepreneurs and investors are congruent with the convergence-of-interest perspective argued in the seminal work of Morck et al. (1988). However, given the observed nonsignificance of the investment size's direct effect, Figure 2 summarizes the outcomes by showing that the direct effect of investor know-how and the indirect effect from that know-how (due to its interaction with the investment size) have opposite impacts on the entrepreneur's ownership share, although we posited positive impacts of both effects at both stages. That is, in Figure 2(a) the direct effect increases the entrepreneur's share and the indirect effect decreases it, while in Figure 2(b) the direct effect decreases the entrepreneur's share and the indirect effect increases it. We thus observe deviations from our stewardship-based hypotheses, whereby $\mathrm{H3}$ is supported while $\mathrm{H5}$ is opposed, and $\mathrm{H4}$ is opposed while $\mathbf{H 6}$ is supported.

From a managerial perspective, estimating the size and impact of know-how is always a challenging undertaking. As of now, we are unaware of any guidelines for establishing investor know-how-based contracts (e.g., how to value stage 1 vs. stage 2 know-how) or any theory driven estimations that link the value of the bounds on the investment size $k$ with the levels of two types of knowhow. These deal-specific bounds that are posited in H1, illustrated in Figure 1, and formalized in Appendix A, offer useful managerial guidelines for writing such contracts. We should also add that although these bounds that drive our first hypothesis (H1) are intuitive, they build confidence in the underlying formal model we built. The not-so-intuitive results (especially in H5 and H6) are then explained by the solution of the optimal problem as a helpful rationale (i.e., it addresses the "why") for the proposed contractual relationships within these bounds.

We also document elasticity values (e.g., at the development stage). Raising the scaled investment size from a standard deviation below the mean to a standard deviation above the mean leads to a $22.6 \%$ reduction in the entrepreneur's ownership share based on the outcomes in Figure 2, which can serve as benchmarks. Moreover, the diverging and converging effects shown in Figure 2 create tradeoffs in terms of simultaneously increasing the level of investment, levels of investor know-how, and associated assignment of the entrepreneur's ownership share while writing contracts aimed to inform parties that consider such contracts.

These findings, while useful in practice, face a critical limitation. When considering the investor's know-how in financial contracts, the interests of the entrepreneur and investor could diverge (Collewaert \& Sapienza, 2014), although the stewardship perspective we used assumes that their interests converge. However, the prediction of entrenchment theory, also examined by Morck et al. (1988), considers the possibility of a lack of convergence of interest 
between the entrepreneur and the investor regarding ownership sharing. The prediction of entrenchment perspective thus accounts for the possibility of agency conflicts on the part of the agent's (entrepreneur's) vis-à-vis the principal's (investor's) interest while setting up contracts and awarding ownership shares.

Morck and Yeung (2003) apply the agency theory within the family business literature to argue that ownership shares should favor the investor. Wasserman (2006), on the other hand, juxtaposes agency and stewardship issues and suggests that entrepreneurs who retain more control will experience lower financial returns, while those giving up control will retain more equity stakes. Certhoux and Perrin (2013) examine instead mechanisms (e.g., favorable and unfavorable elements) for knowledge transfer between an angel and an entrepreneur, while Chemmanur and Chen (2014) focus on the dynamics behind the evolution of investment contracts (from both angels and venture capitalists). These various dynamics are important because investor know-how (e.g., in stage 1 vs. stage 2) differs in terms of the timing of the observations. Stage 2 know-how is not observed until after the deferred cash from the contract has been delivered. Thus, some investors may be more open to the specter of agency issues while writing their contracts for stage 2 know-how. This scenario would lead to contracts that would be consistent with the negative but significant effect that prompted the rejection of $\mathbf{H 4}$.

The negative but significant effect that prompted the rejection of $\mathbf{H 5}$ may be more nuanced, however. A simultaneous increase in the investment size and stage 1 know-how provided by the investor could compound the agency conflict between the investor and the entrepreneur because it will raise screening, contracting, and monitoring costs (Kaplan \& Stromberg, 2003). For instance, the need for more funding could raise the possibility of renegotiation, exit or incorporation of an additional investor at the end of stage 1, and such bargaining would negate the possibility of a higher ownership share for the entrepreneur based on the entrenchment perspective (Bartlett, 2006). Given these theoretical arguments, extending our formal analysis based on the agency theory, particularly for stage 2 know-how, would be a worthwhile endeavor. Investors may be rewarded with larger ownership shares if they deploy more stage 2 know-how because their know-how enhances the venture's alignment with market mechanisms and mitigates opportunistic behavior of the entrepreneur.

\section{Conclusion}

Overall, we offer a stewardship theory-based analysis of a body of evidence on structuring staged-based contracts ex-ante if the value created from either early-stage work or follow-on growth-related work is conditioned upon the level of know-how that the investor brings to the new business venture. Our results extend the role of stage-based inconsistencies, where alternative theories appear to be needed to explain observations in different stages of the lifecycle of an enterprise, into the realm of writing contracts contingent on investor know-how. We think about such inconsistencies in two distinct ways: (a) when the two ex-ante unknown levels of the investor's know-how are made available, and (b) when the entrepreneur values the investor's know-how in development stage 1 in terms of contract continuation (i.e., considering the lower bound on the investor's know-how $\bar{L}_{1}$ when moving from stage 1 to stage 2). Stage-based inconsistencies arise because these three events - the investor's delivery of know-how in stage 1, the investor's decision to continue into stage 2 , and the investor's delivery of know-how in stage 2 - take place at different points in time, and the entrepreneur's or investor's ability to estimate values may be altered based on inconsistent anticipation of contract constructs across stages.

These inconsistencies are not new to the entrepreneurship literature (e.g., see Manigart, De Waele, Wright, Robbie, Desbrières, Sapienza, \& Beekman, 2002, who examine business risk 
diversification vs. specialization strategies using finance theory and the resource-based view), but finding them is new when structuring ex-ante stage-based contracts that are contingent on investor know-how. From a theory perspective, this builds the case for explicitly modeling and observing stage-based preferences and behavioral biases for both parties (Frederick, Loewenstein, \& O'Donoghue, 2002). Leung, Foo, and Chaturvedi (2013) show that an entrepreneur's preference for human resources across start-up and growth phases (or, equivalently, development stage 1 and growth stage 2) can also vary based on prior experience.

The entrepreneur's ability to anticipate and observe the delivered know-how and the resulting impact on the venture's value also brings additional challenges in writing meaningful contracts for investor know-how in two-stage settings. Recently, contracts for entrepreneurs who are crowdfunded through AngelList (2016) have provided improved mechanisms to more readily track investors' abilities and quantify investment size effects. Some investment aggregation firms, like OurCrowd (2016), select their crowdfunding business angels not only based on their ability to contribute cash, but also based on their know-how of the context-specific aspects of each start-up deal and endow them with a seat on the board. ${ }^{10}$ The question of how to quantify investor know-how and its tradeoff with the investment size, instead of merely examining equity incentives, is becoming even more salient in the angel investment space.

Future research should go beyond funder selection for crowdfunding based on their ability not only to contribute cash and know-how, but also scrutinize the engagement (and thus knowhow) of users/consumers in value creation. For instance, in the platform (or network) economy populated by mobile technologies, both entrepreneurs and investors should consider involving users as early as in the idea development stage. User empowerment is becoming increasingly relevant as early-stage ventures rely on agile and lean business development approaches, where users can easily be involved (de Jong \& van Dijk, 2015). More engaged users can bring complementary know-how that impact firm valuation, which in turn provides new opportunities and challenges to early-stage entrepreneurs and their potential investors. Investigating user engagement thus offers a fertile ground for further research on not only how investor know-how, but also how user know-how can shape ownership sharing in stage-based contracts.

Lastly, relaxing our assumption on the allocation of bargaining power is another fruitful avenue for further research. For instance, Repullo and Suarez' (2004) approach transfers the bargaining power to the investor effective at the beginning of growth stage 2 , when both parties renegotiate the terms of the contract. This delay of bargaining power reallocation is consistent with a scenario where there exists a lack of knowing whether the angel's level of know-how should allow him/her to possess such power, but after observing stage 1 know-how, both parties realize the angel's potential for stage 2 . The investor could thus augment his or her ownership share by extracting an additional fraction of the entrepreneur's share. By the end of stage 1, the entrepreneur must thus anticipate this dilution effect from renegotiation. As the changes in our formal model come down to reducing by a certain fraction the entrepreneur's share, the hypotheses we put forward are qualitatively unaffected. Nevertheless, we acknowledge that this is only one avenue and many more could be taken for relaxing our assumptions.

\section{Appendix}

\section{Appendix A: Mathematical Formulation and Proof of $\mathrm{HI}$}

In our formulation, the timeline of events proceeds as follows. At the start of stage 1, the entrepreneur (who holds the bargaining power) establishes the contract's terms for value sharing with the investor based on an ownership share $s \in[0,1]$ for the entrepreneur (thus 
$[1-s]$ for the investor) and the distribution of a total cash infusion amount, $k$. At the end of stage 1, the entrepreneur can observe the investor's value contribution $L_{1}^{a}$ based on his or her technological know-how, and an initial investment amount $k_{1}(\geq 0)$. For the partnership to avoid termination, the investor must sufficiently improve the venture's value $V$ over that stage. The entrepreneur then receives the remaining cash $k_{2}\left(=k-k_{1}\right)$ at the start of stage 2. At the end of stage 2, the entrepreneur can observe the investor's value contribution $L_{2}^{b}$ from his or her market-related know-how, and both parties then assess the overall value of the business venture.

To characterize the entrepreneur's ownership share $s^{*}$ and investment allocation between $k_{1}^{*}$ and $k_{2}^{*}$, which maximize the entrepreneur's expected payoffs (as a share of venture value), we begin the analysis with stage 2 and move backward to stage 1 . That is, we first consider stage 2, assuming that the investor's level of know-how $L_{1}$ is known and assuming that both parties have agreed to continue to stage 2 . Based on the overall value of the firm that takes the form of a Cobb-Douglas production function, that is, $V\left(p, L_{1}, L_{2}\right)=p L_{1}^{a} L_{2}^{b}$, the expected payoffs for the entrepreneur (EN) and investor (IN) are, respectively, $E\left[\pi_{E N} \mid L_{1}\right]=$ $\operatorname{sp} L_{1}^{a} E\left[L_{2}^{b}\right]$ and $E\left[\pi_{I N} \mid L_{1}\right]=[1-s] p L_{1}^{a} E\left[L_{2}^{b}\right]-k_{2}$, where $E$ denotes the expectation operator. ${ }^{11}$ These payoffs are also equivalent to $E\left[\pi_{E N} \mid L_{1}\right]=s p L_{1}^{a} \frac{v^{b}}{b+1}$ and $\left.E\left[\pi_{I N} \mid L_{1}\right]=[1-s] p L_{1}^{a} \frac{v^{b}}{b+1}-k_{2}\right)$, since the expected value can be computed with an integral encompassing all possible values of the random variable $L_{2}$ based on the fact that $E\left[L_{2}^{b}\right]=\int_{0}^{v} L_{2}^{b} d F\left(L_{2}\right)=\int_{0}^{v} L_{2}^{b} \frac{1}{v} d L_{2}=\frac{v^{b}}{b+1}$ (Hoel, Port, \& Stone, 1971). Moving backward to solve for stage 1 , the investor imposes a continuation constraint on the entrepreneur, whereby the investor will cease the contract if his or her payoffs do not cover the portion of investment deferred to stage 2. Formally,

$$
E\left[\pi_{I N} \mid L_{1}\right]=[1-s] p L_{1}^{a} \frac{v^{b}}{b+1}-k_{2} \geq 0
$$

Since the right-hand side of Eq. (A1) equals zero, the minimum reservation payoff $R$ to be earned by the investor, which could also account for his or her time value of money, is set to zero. However, we have verified that setting $R$ to zero to simplify exposition is without loss of generality (i.e., all of our qualitative results from the formal framework that lead to our hypotheses still hold true).

When the continuation constraint in Eq. (A1) binds (i.e., $\geq$ becomes $=$ ), it imposes a lower bound on $L_{1}$, above which the investor should maintain his or her commitment into stage 2 because the investor's payoff is sufficiently high; formally $\bar{L}_{1} \equiv\left[\frac{[b+1] k_{2}}{p[1-s] v^{b}}\right]^{\frac{1}{a}}$. In effect, the realized value of the venture does not justify further investment below $\bar{L}_{1}$. Thus we must set this lower bound on the random variable $L_{1}$ to evaluate expected values at stage 1 that account only for levels of the investor's know-how at stage 1 for which the investor remains involved in stage 2 .

Eq. (A2) summarizes what we seek: a financing contract comprised of an optimal ownership share $s^{*}$ for the entrepreneur and an optimal deferred investment $k_{2}^{*}$, which maximize the entrepreneur's expected payoff (Eq. A2a) subject to a deal-participation constraint (Eq. A2b, which will bind at optimality) where the investor's expected payoff is sufficient to stimulate him or her to invest the total contracted amount (Eq. A2c) in the new business prospect. Formally,

$$
\max _{s \in[0,1], k_{1}>0, k_{2} \geq 0} \int_{\bar{L}_{1}}^{\mu}\left[s p L_{1}^{a} \frac{v^{b}}{b+1}\right] d F\left(L_{1}\right)
$$




$$
\begin{gathered}
\text { subject to } \int_{\bar{L}_{1}}^{\mu}\left[[1-s] p L_{1}^{a} \frac{v^{b}}{b+1}-k_{2}\right] d F\left(L_{1}\right)-k_{1} \geq 0 \\
\text { and } k_{1}+k_{2}=k .
\end{gathered}
$$

We now solve this optimization problem to characterize the optimal financing contract. The (unconditional) expected payoffs are, respectively, $E\left[\pi_{I N}\right]=\int_{\bar{L}_{1}}^{\mu}\left[[1-s] p L_{1}^{a} v^{b}-k_{2}\right] d F\left(L_{1}\right)-k_{1}$ and $E\left[\pi_{E N}\right]=\int_{\bar{L}_{1}}^{\mu}\left[s p L_{1 \frac{\nu^{b}}{b+1}}\right] d F\left(L_{1}\right)$. For a uniform (continuous) probability distribution on $[0, \mu]$,

$$
\begin{aligned}
& \int_{\bar{L}_{1}}^{\mu} d F\left(L_{1}\right)=\int_{\left[\frac{[b+1] k_{2}}{p[1-s] \nu^{b}}\right]^{\frac{1}{a}}}^{\mu} d L_{1}=1-\frac{1}{\mu}\left[\frac{[b+1] k_{2}}{p[1-s] v^{b}}\right]^{\frac{1}{a}} \text { and } \\
& \int_{\bar{L}_{1}}^{\mu} L_{1}^{a} d F\left(L_{1}\right)=\int_{\left[\frac{\left[b+1 k_{2}\right.}{p[1-s] b^{b}}\right]^{\frac{1}{a}}}^{\mu} \frac{L_{1}^{a}}{\mu} d L_{1}=\frac{\mu^{a}}{a+1}-\frac{1}{[a+1] \mu}\left[\frac{[b+1] k_{2}}{p[1-s] \nu^{b}}\right]^{\frac{a+1}{a}}
\end{aligned}
$$

Consequently, with $k=k_{1}+k_{2}$,

$$
\begin{aligned}
E\left[\pi_{I N}\right] & =\frac{p[1-s] \mu^{a} v^{b}}{[a+1][b+1]}+k_{2}^{\frac{a+1}{a}} \frac{a}{[a+1] \mu}\left[\frac{b+1}{p[1-s] \nu^{b}}\right]^{\frac{1}{a}}-k \quad \text { and } \\
E\left[\pi_{E N}\right] & =\frac{p s v^{b}}{[a+1][b+1] \mu}\left\{\mu^{1+a}-\left[\frac{[b+1] k_{2}}{p[1-s] \nu^{b}}\right]^{\frac{a+1}{a}}\right\}
\end{aligned}
$$

The sufficient condition for the investor's participation (or binding of Eq. 1), that is, $E\left[\pi_{I N}\right]=0$, yields

$$
k_{2}^{*}(s)=\left\{\frac{\mu}{a[b+1]}\left[\frac{p[1-s] \nu^{b}}{b+1}\right]^{\frac{1}{a}}\left[[a+1][b+1] k-p[1-s] \mu^{a} v^{b}\right]\right\}^{\frac{a}{a+1}} .
$$

Inserting $k_{2}^{*}$ into $E\left[\pi_{E N}\right]$ yields $E\left[\pi_{E N}\left(k_{2}^{*}\right)\right]=\frac{p s \mu^{a} v^{b}}{a[b+1]}-\frac{k s}{a[1-s)}$, which has two roots $s_{R_{1}}=0$ and $s_{R_{2}}=1-\frac{[b+1] k}{p \mu^{a} v^{b}}$; i.e., $\left.E\left[\pi_{E N}\left(k_{2}^{*}\right)\right]\right|_{s_{R_{1}}}=\left.E\left[\pi_{E N}\left(k_{2}^{*}\right)\right]\right|_{s_{R_{2}}}=0$. Taking the first- and second-order derivatives of $E\left[\pi_{E N}\left(k_{2}^{*}\right)\right]$ with respect to $s$ yields $\frac{\partial E\left[\pi_{E N}\left(k_{2}^{*}\right)\right]}{\partial s}=\frac{p \mu^{a} v^{b}}{a[b+1]}-\frac{k}{a[1-s]^{2}} \quad$ and $\frac{\partial^{2} E\left[\pi_{E N}\left(k_{2}^{*}\right)\right]}{\partial s^{2}}=\frac{-2 k}{a[1-s]^{3}}$.

We note that $0 \leq \frac{p \mu^{a} v^{b}}{[a+1]^{2}[b+1]}<\frac{p \mu^{a} v^{b}}{[a+1][b+1]}<\frac{p \mu^{a} v^{b}}{b+1}$. We also note that $E\left[\pi_{E N}\left(k_{2}^{*}\right)\right]$ is concave (i.e., inverted U-shaped) and $\tilde{s}=1-\sqrt{\frac{b+1 \mid k}{p \mu^{a} v^{b}}}$ maximizes the entrepreneur's expected payoff. The optimal investment for the stage 2 is then $k_{2}^{*}(\tilde{s})=\left\{\frac{\mu k}{a}\left[\sqrt{\frac{k p v^{b}}{[b+1] \mu^{a}}}\right]^{\frac{1}{a}}\left[[a+1]-\sqrt{\frac{p \mu^{a} v^{b}}{[b+1] k}}\right]\right\}^{\frac{a}{a+1}}$. Moreover, $k_{2}^{*} \geq 0$ if and only if $s \geq \hat{s} \equiv 1-\frac{[a+1][b+1] k}{p \mu^{a} v^{b}}$. In other words, $k_{2}^{*}$ is the amount of 
stage 2 investment at which the investor agrees to participate, and it remains nonnegative as long as the entrepreneur's ownership share equals or exceeds $\hat{s}$. We note that $s_{R_{2}}>\tilde{s}$ if and only if $k<\frac{p \mu^{a} v^{b}}{b+1}$, and $s_{R_{2}}>\hat{s}$ since $a>0$ by definition.

Since we must consider the sign of $k_{2}^{*}$ and of $E\left[\pi_{E N}\left(k_{2}^{*}\right)\right]$, both of which must be nonnegative, we divide this proof in four parts: (1) when $k \in\left[0, \frac{p \mu^{a} \nu^{b}}{[a+1]^{2}[b+1]}\right]$; (2) when $k \in\left[\frac{p \mu^{a} v^{b}}{[a+1]^{2}[b+1]}, \frac{p \mu^{a} v^{b}}{[a+1][b+1]}\right]$; (3) when $k \in\left[\frac{p \mu^{a} v^{b}}{[a+1][b+1]}, \frac{p \mu^{a} v^{b}}{b+1}\right]$, and (4) when $k \in\left[\frac{p \mu^{a} v^{b}}{b+1}, \infty\right]$. We also accompany each part with a graphical representation to ease readability.

1. If $k \in\left[0, \frac{p \mu^{a} v^{b}}{[a+1]^{2}[b+1]}\right]$, then $0 \leq \tilde{s} \leq \hat{s}$. Given that $s_{R_{2}}>\tilde{s}$ and $s_{R_{2}}>\hat{s}, E\left[\pi_{E N}\left(k_{2}^{*}\right)\right]$ is positive and decreases with $s$ when $s>\tilde{s}$, and given that $k_{2}^{*} \geq 0$ for any $s \geq \hat{s}$, the entrepreneur maximizes his or her payoff at $\hat{s}\left(\right.$ with $k_{2}^{*}(\hat{s})=0$ ), as illustrated in Figure A1.1.

2. If $k \in\left[\frac{p \mu^{a} v^{b}}{[a+1]^{2}[b+1]}, \frac{p \mu^{a} v^{b}}{[a+1][b+1]}\right]$, then $0 \leq \hat{s} \leq \tilde{s}$. Given that $s_{R_{2}}>\tilde{s}$ and $s_{R_{2}}>\hat{s}, E\left[\pi_{E N}\left(k_{2}^{*}\right)\right]$ is positive and increases with $s$ when $s \in[0, \tilde{s}]$, and given that $k_{2}^{*} \geq 0$ for any $s \geq \hat{s}$, the entrepreneur maximizes his or her payoff at $\tilde{s}$, as illustrated in Figure A1.2.

3. If $k \in\left[\frac{p \mu^{a} v^{b}}{[a+1][b+1]}, \frac{p \mu^{a} v^{b}}{b+1}\right]$, then $\hat{s} \leq 0 \leq \tilde{s}$. Given that $s_{R_{2}}>\tilde{s}$ and $s_{R_{2}}>\hat{s}, E\left[\pi_{E N}\left(k_{2}^{*}\right)\right]$ is positive and increasing with $s$ when $s \in[0, \tilde{s}]$, and given that $k_{2}^{*} \geq 0$ for any $s \geq 0$, the entrepreneur again maximizes his or her payoff at $\tilde{s}$, as illustrated in Figure A1.3.

4. If $k \in\left[\frac{p \mu^{a} v^{b}}{b+1}, \infty\right]$, then $s_{R_{2}} \leq \hat{s} \leq \tilde{s} \leq 0$ and $E\left[\pi_{E N}\left(k_{2}^{*}\right)\right]$ is positive only for a negative value of $s$. Consequently, no investment should be made, as illustrated in Figure A1.4.

H1 follows from using $K_{L B} \equiv \frac{p \mu^{a} v^{b}}{[a+1]^{2}[b+1]}$ and $K_{U B} \equiv \frac{p \mu^{a} v^{b}}{[b+1]}$ and summarizing the above development:

(a) no investment should be made if $k>K_{U B}$;

(b) $s^{*}=1-\frac{[a+1][b+1] k}{p \mu^{a} \nu^{b}}$ and $k_{1}^{*}=k\left(k_{2}^{*}=0\right)$ if $0<k \leq K_{L B}$;

(c) $s^{*}=1-\sqrt{\frac{[b+1] k}{p \mu^{a} \nu^{b}}}, \quad k_{1}^{*}=k-k_{2}^{*} \quad$ with $\quad k_{2}^{*}=\left\{\frac{\mu k}{a}\left[\sqrt{\frac{k p v^{b}}{[b+1] \mu^{a}}}\right]^{\frac{1}{a}}\left[[a+1]-\sqrt{\frac{p \mu^{a} v^{b}}{[b+1] k}}\right]\right\}^{\frac{a}{a+1}} \quad$ if
$K_{L B}<k \leq K_{U B}$.

\section{Appendix B: Sensitivity Analysis}

By taking the first-order derivative of $s^{*}$ in $\mathbf{H 1}(\mathrm{b})$ or H1(c) with respect to the corresponding parameter, we straightforwardly obtain: for $\mathbf{H 2}, \frac{\partial s^{*}}{\partial k}<0$; for $\mathbf{H 3}, \frac{\partial s^{*}}{\partial \mu}>0$; for $\mathbf{H 4}, \frac{\partial s^{*}}{\partial v}>0$; for H5, $\frac{\partial^{2}\left[s^{*}\right]}{\partial k \partial \mu}>0$, and for H6, $\frac{\partial^{2}\left[s^{*}\right]}{\partial k \partial v}>0$. We also obtain for the productivity factor (a control variable) that $\frac{\partial s^{*}}{\partial p}>0$.

Furthermore, Figure 1 and the rationale we put forward for $\mathbf{H 3}$ and $\mathbf{H 4}$ depends on the sensitivity of $k_{2}^{*}$ in H1(c). For Figure 1, we observe that $k_{2}^{*}$ increases with an increase in $k$ since each term becomes larger and $a>0$. That is, $\frac{\partial k_{2}^{*}}{\partial k}>0$ (similarly $\frac{\partial\left[k_{2}^{*} / k\right]}{\partial k}>0$ ). 


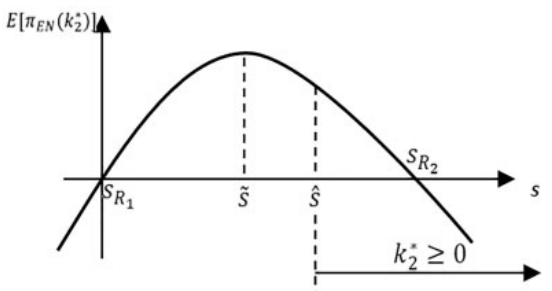

1. $0 \leq \tilde{s} \leq \hat{s}$

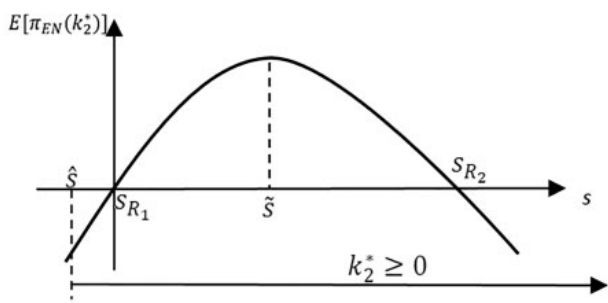

3. $\hat{s} \leq 0 \leq \tilde{s}$

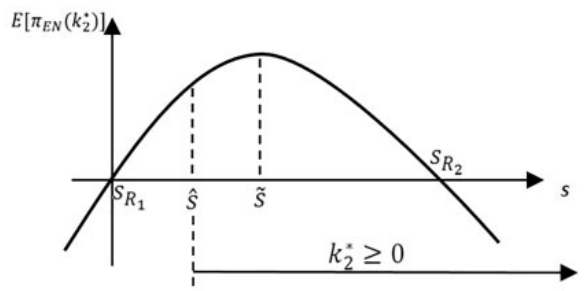

2. $0 \leq \hat{s} \leq \tilde{s}$

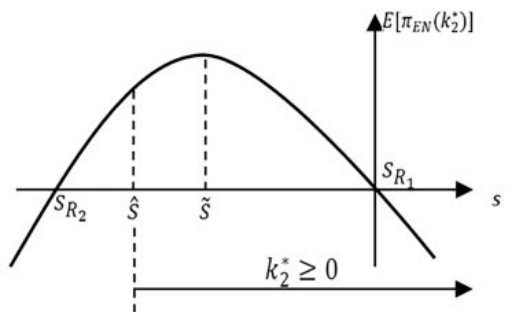

4. $s_{R_{2}} \leq \hat{s} \leq \tilde{s} \leq 0$

Figure Al. Optimal ownership and investment agreement

For explaining H3, we observe that $\frac{\partial k_{2}^{*}}{\partial \mu}<0$ if $\frac{\partial}{\partial \mu}\left[\mu^{\frac{1}{2}}\left[[a+1]-\left[\frac{p \mu^{a} v^{b}}{[b+1] k}\right]^{\frac{1}{2}}\right]\right]<0$, that is, if $\frac{1}{2} \mu^{-\frac{1}{2}}\left[[a+1]-\left[\frac{p \mu^{a} v^{b}}{[b+1] k}\right]^{\frac{1}{2}}\right]-\frac{1}{2} \mu^{-\frac{1}{2}} a\left[\frac{p \mu^{a} \nu^{b}}{[b+1] k}\right]^{\frac{1}{2}}<0$, that is, if $\frac{1}{2} \mu^{-\frac{1}{2}}\left[[a+1]-\left[\frac{p \mu^{a} v^{b}}{[b+1] k}\right]^{\frac{1}{2}}-a\left[\frac{p \mu^{a} v^{b}}{[b+1] k}\right]^{\frac{1}{2}}\right]<0$

that is, if $[a+1]\left\{1-\sqrt{\frac{p \mu^{a} v^{b}}{[b+1] k}}\right\}<0$ or, equivalently, if $\frac{p \mu^{a} v^{b}}{[b+1]}>k$. Since this condition holds true in H1(c) where $k_{2}^{*} \neq 0$, it follows that $\frac{\partial k_{2}^{*}}{\partial \mu}<0$. Similarly for explaining $\mathbf{H 4}, \frac{\partial k_{2}^{*}}{\partial v}<0$ if $\frac{\partial}{\partial \nu}\left[v^{\frac{b}{2 a}}\left[[a+1]-\left[\frac{p \mu^{a} v^{b}}{[b+1] k}\right]^{\frac{1}{2}}\right]\right]<0$ or, equivalently, if $\frac{b}{2 a} \nu^{\frac{b}{2 a}}-1\left[[a+1]-\left[\frac{p \mu^{a} v^{b}}{[b+1] k}\right]^{\frac{1}{2}}\right]-\frac{1}{2} v^{\frac{b}{\nu^{2 a}}-1} b\left[\frac{p \mu^{a} v^{b}}{[b+1] k}\right]^{\frac{1}{2}}$ $<0$, which again reduces to $\frac{p \mu^{a} \nu^{b}}{[b+1]}>k$ and $\frac{\partial k_{2}^{*}}{\partial \nu}<0$.

\section{Appendix C: Index of Similarity Calculation}

We allocate the vector $P_{i}=(1,1,1,1,1,1)$ to an "ideal" entrepreneur who possesses all 6 experiences listed in the main body of this article. However, for an entrepreneur with more limited experience in that, for instance, among the six categories he or she only experienced leading other 
new ventures that succeeded and worked at significant large-firm, we allocate the vector $(0,1,1,0,0,0)$. Next, to assess how close experience-wise deal $x$ 's entrepreneur is to the "ideal" entrepreneur, we calculate a similarity index $S_{x i}$. That is, we obtain a normalized experience count of deal $x$ 's entrepreneur by calculating $S_{i x}=\frac{P_{x} P_{i}}{\left|P_{x}\right|\left|P_{i}\right|}$, where $P_{x} P_{i}$ is the product of the two vectors $P_{x}$ and $P_{i}$, while $|\cdot|$ is the length of the vector (calculated as the square root of the sum of the squared components). We say "normalized" since if the experience vector for deal $x$ 's entrepreneur is $(1,1,1,1,1,1)$ or, in other words, this entrepreneur is "ideal," then

$$
S_{x i}=\frac{(1,1,1,1,1,1)(1,1,1,1,1,1)}{\sqrt{6} \sqrt{6}}=\frac{(1 \times 1+1 \times 1+1 \times 1+1 \times 1+1 \times 1+1 \times 1)}{\sqrt{6} \sqrt{6}}=1,
$$

but if that entrepreneur has no experience in the highlighted categories, his or her experience vector becomes $(0,0,0,0,0,0)$ and $S_{x i}=0$. Moreover, as illustrated above, if the experience vector for deal $x$ 's entrepreneur is $(0,1,1,0,0,0)$, then

$$
S_{x i}=\frac{(1,1,1,1,1,1)(0,1,1,0,0,0)}{\sqrt{2} \sqrt{6}}=\frac{(0 \times 1+1 \times 1+1 \times 1+0 \times 1+0 \times 1+0 \times 1)}{\sqrt{2} \sqrt{6}}=0.5774 .
$$

\section{Acknowledgments}

We are grateful for the insightful and constructive suggestions from participants to paper presentation sessions at the 2015 Annual Conference of the Production and Operations Management Society, Washington D.C., the 2015 Academy of Management Meeting, Vancouver, Canada, and participants to a 2016 invited research seminar at the National University of Singapore's Division of Engineering and Technology Management.

\section{Declaration of Conflicting Interests}

The author(s) declared no potential conflicts of interest with respect to the research, authorship, and/or publication of this article.

\section{Funding}

The author(s) received no financial support for the research, authorship, and/or publication of this article.

\section{Notes}

I. We note that, for both stages, the investor's know-how (once realized) is therefore dynamic in that it varies based on the deal and the investor, who can then gain more know-how as he or she assesses more deals over time.

2. This is particularly evident for firms with large valuations compared to established players (e.g., WhatsApp's acquisition by software giant Facebook; see Gelles, 20l4), even if their asset base, and thus their investment size, was relatively small (WhatsApp was largely funded by angels, with a small amount of investment compared to their valuation; Cortle \& Doyle, 2014).

3. In some cases, the AIPP angels restructured their contracts ex-post; we excluded such deals in our sample.

4. Our analysis discusses the significance of totalinvested as it highly correlates with the dependent variable.

5. Scholarly works that have used a similar indexing approach include Lee (2008), who quantifies firm capabilities with respect to product market, and Baker (1992) and Kaarboe and Olsen (2008), who measure performance.

6. We verified that the relationships and effects posited in $\mathbf{H 2}$ to $\mathbf{H 6}$ (and mathematically proven in Appendix B) are unaffected by the logarithmic transformation of their respective variables. 
7. This split is consistent with the entire AIPP dataset, where angels made follow-on investments in only $29 \%$ of the ventures that they had invested in (Wiltbank \& Boeker, 2007), noting that the AIPP data was recorded until the angel exited the deal. Some ventures may have had no need for further funding prior to a successful exit, such as those ventures reporting to have been "bought by another firm" or that pursued an IPO. Others experienced a less desirable exit such as "ceased operations," but even a subset of these deals received follow-up rounds of funding.

8. We rely on the full model (i.e., Model 3) because these regression coefficients are not significant in Model 2.

9. We also note a multivariate specification for Model 3 (i.e., the dependent variable is associated with both In $\mu$ and $\ln v$, and their interactions with $\ln k$ ). We ran a Sobel test on the measure $\frac{\delta_{1} \times \beta_{2}^{\prime \prime}}{\text { pooled standard err }}$ based on model $M_{1}$ and Model 3 , and this test was significant $(p<.0 \mathrm{I})$. We also ran a Sobel test on the measure $\frac{\delta_{1}^{\prime} \times \beta_{3}^{\prime \prime}}{\text { pooled standard error }\left(\delta_{1}^{\prime}, \beta_{3}^{\prime \prime}\right)}$ based on model $M_{2}$ and Model 3 , and this test was also significant $(p<.05)$. That is, both mediation effects are statistically significant. To illustrate moderated mediation (Dawson, 2014), we further characterize these multivariate interactions as part of our discussion in the next section and in Figure 2, where the effects of the investor's know-how (at both stages) and the investment size are separately displayed.

10. An example is the funding of Sight Diagnostics, a computer-vision-based medical device start-up that allows for cheaper, faster, and fully automated blood diagnostics for malaria testing markets (Sightdx, 20l6).

II. A general agreement exists on the propensity of entrepreneurs to be risk-takers. However, Caliendo, Fossen, and Kritikos (2009) sample of self-employed individuals exhibited $79 \%$ of low to medium willingness to take risks, while the majority of entrepreneurs (and students) in Elston and Audretsch's (2010) sample were risk-averse. Burmeister-Lamp, Lévesque, and Schade (20I2) also found in their sample a majority of risk-averse entrepreneurs. This divergence encouraged us to formulate a simpler framework where the entrepreneur is risk-neutral.

\section{References}

AngelList. (2016). AngelList. Retrieved August 22, 2016, from https://en.wikipedia.org/wiki/AngelList

Arthurs, J. D., \& Busenitz, L. W. (2003). The boundaries and limitations of agency theory and stewardship theory in the venture capitalist/entrepreneur relationship. Entrepreneurship Theory and Practice, 28(2), 145-162.

Baker, G. P. (1992). Incentive contracts and performance measurement. Journal of Political Economy, $100(3), 598-614$.

Baron, R. M., \& Kenny, D. A. (1986). The moderator-mediator variable distinction in social psychological research: Conceptual, strategic, and statistical considerations. Journal of Personality and Social Psychology, 51(6), 1173-1182.

Bartlett, R. P. (2006). Venture capital, agency costs, and the false dichotomy of the corporation. UCLA Law Review, 54(6), 37-116.

Burchardt, J., Hommel, U., Kamuriwo, D. S., \& Billitteri, C. (2014). Venture capital contracting in theory and practice: Implications for entrepreneurship research. Entrepreneurship Theory and Practice, 40(1), 25-48.

Burmeister-Lamp, K., Lévesque, M., \& Schade, C. (2012). Are entrepreneurs influenced by risk attitude, regulatory focus or both? An experiment on entrepreneurs' time allocation. Journal of Business Venturing, 27(4), 456-476.

Caliendo, M., Fossen, F. M., \& Kritikos, A. S. (2009). Risk attitudes of nascent entrepreneurs-new evidence from an experimentally validated survey. Small Business Economics, 32(2), 153-167.

Certhoux, G., \& Perrin, A. (2013). Business angels' practices in the screening stage: A study of knowledge transfer to the entrepreneur. 13th EURAM Conference, Istanbul.

Chemmanur, T. J., \& Chen, Z. (2014). Venture capitalists versus angels: The dynamics of private firm financing contracts. Review of Corporate Finance Studies, 3(1-2), 39-86.

Colombo, M. G., \& Grilli, L. (2005). Founders' human capital and the growth of new technology-based firms: A competence-based view. Research Policy, 34(6), 795-816.

Cortle, P., \& Doyle, B. (2014). Where are the five mysterious former yahoo employees? Retrieved March 1, 2017, from http://startupbook.co/2014/02/23/best-investment-ever-five-former-employees-whose250000-turned-into-800-million/ 
Collewaert, V., \& Manigart, S. (2016). Valuation of angel-backed companies: The role of investor human capital. Journal of Small Business Management, 54(1), 356-372.

Collewaert, V., \& Sapienza, H. J. (2014). How does angel investor-entrepreneur conflict affect venture innovation? It depends. Entrepreneurship Theory and Practice, 40(3), 573-597.

Dahiya, S., \& Ray, K. (2012). Staged investments in entrepreneurial financing. Journal of Corporate Finance, 18(5), 1193-1216.

Dahl, D. (2010). The 2010 business valuation guide. Retrieved February 5, 2017, from www.inc.com/ magazine/20101101/the-2010-business-valuation-guide.html \& http://images.inc.com/magazine/ 20101101/ValuationGuide2010.pdf

Davis, J. H., Schoorman, F. D., \& Donaldson, L. (1997). Toward a stewardship theory of management. Academy of Management Review, 22(1), 20-47.

Dawson, J. F. (2014). Moderation in management research: What, why, when, and how. Journal of Business and Psychology, 29(1), 1-19.

de Bettignies, J., \& Brander, J. A. (2007). Financing entrepreneurship: Bank finance versus venture capital. Journal of Business Venturing, 22(6), 808-832.

Eckhardt, J. T., \& Shane, S. (2006). Multistage selection and the financing of new ventures. Management Science, 52(2), 220-232.

Elston, J. A., \& Audretsch, D. B. (2010). Risk attitudes, wealth and sources of entrepreneurial start-up behavior. Journal of Economic Behavior and Organization, 76(1), 82-89.

Fox, M. A., \& Hamilton, R. T. (1994). Ownership and diversification: Agency theory for stewardship theory. Journal of Management Studies, 31(1), 69-81.

Frederick, S., Loewenstein, G., \& O'Donoghue, T. (2002). Time discounting and time preference: A critical review. Journal of Economic Literature, 40(2), 351-401.

Freedman, J. H. (2012). "No." "No." "No." "No." "Yes!" Inc. Magazine, 34(4), 74-82.

Gelles, D. (2014). Facebook's \$21.8 billion whatsapp acquisition. Retrieved March 1, 2017, from https:// dealbook.nytimes.com/2014/10/28/facebooks-21-8-billion-acquisition-lost-138-million-last-year/?

Guthrie, J. (2001). The management, measurement and the reporting of intellectual capital. Journal of Intellectual capital, 2(1), 27-41.

Hayes, A. F., \& Scharkow, M. (2013). The relative trustworthiness of inferential tests of the indirect effect in statistical mediation analysis: Does method really matter? Psychological Science, 24(10), 1918-1927.

Hoel, P. G., Port, S. C., \& Stone, C. J. (1971). Introduction to probability theory. Boston, MA: Houghton Mifflin.

Ibrahim, D. M. (2008). The (not so) puzzling behavior of angel investors. Vanderbilt Law Review, 61(5), 1405-1452.

Janney, J. J., \& Folta, T. B. (2006). Moderating effects of investor experience on the signaling value of private placements. Journal of Business Venturing, 21, 27-44.

Kaarboe, O. M., \& Olsen, T. E. (2008). Distorted performance measures and dynamic incentives. Journal of Economics \& Management Strategy, 17(1), 149-183.

Kaplan, S. N., \& Strömberg, P. (2003). Financial contracting theory meets the real world: An empirical analysis of venture capital contracts. Review of Economic Studies, 70(2), 281-315.

Kelly, P., \& Hay, M. (2003). Business angel contracts: The influence of context. Venture Capital, 5(4), 287-312.

Koskinen, Y., Rebello, M. J., \& Wang, J. (2014). Private information and bargaining power in venture capital financing. Journal of Economics and Management Strategy, 23(4), 743-775.

Lee, G. K. (2008). Relevance of organizational capabilities and its dynamics: What to learn from entrants' product portfolios about the determinants of entry timing. Strategic Management Journal, 29(12), 1257-1280.

Leung, A., Foo, M. D., \& Chaturvedi, S. (2013). Imprinting effects of founding core teams on HR values in new ventures. Entrepreneurship Theory and Practice, 37(1), 87-106.

Lévesque, M., Joglekar, N., \& Davies, J. (2012). A comparison of revenue growth at recent-IPO and established firms: The influence of SG\&A, R\&D and COGS. Journal of Business Venturing, 27(1), 47-61. 
Lichtenstein, B. M. B., \& Brush, C. G. (2001). How do resource bundles develop and change in new ventures? A dynamic model and longitudinal exploration. Entrepreneurship Theory and Practice, 25(3), 37-58.

Manigart, S., De Waele, K., Wright, M., Robbie, K., Desbrières, P., Sapienza, H. J., ... Beekman, A. (2002). Determinants of required return in venture capital investments: A five-country study. Journal of Business Venturing, 17(4), 291-312.

Mason, C., \& Stark, M. (2004). What do investors look for in a business plan? International Small Business Journal, 22(3), 227-248.

Maxwell, A. L., Jeffrey, S. A., \& Lévesque, M. (2011). Business angel decision making. Journal of Business Venturing, 26(2), 212-225.

Morck, R., \& Yeung, B. (2003). Agency problems in large family business groups. Entrepreneurship Theory and Practice, 27(4), 367-382.

Morck, R., Shleifer, A., \& Vishny, R. W. (1988). Management ownership and market valuation: An empirical analysis. Journal of Financial Economics, 20(1-2), 293-315.

Neal, D. A. (2004). Capital structure for entrepreneurs. FastTrac TechVenture.

Nesta, L., \& Saviotti, P. P. (2006). Firm knowledge and market value in biotechnology. Industrial and Corporate Change, 15(4), 625-652.

OurCrowd. (2016). Build a global startup investment portfolio. Retrieved August 22, 2016, from https:// www.ourcrowd.com

Pahnke, E. C., Katila, R., \& Eisenhardt, K. M. (2015). Who takes you to dance? How funding partners' institutional logics influence innovation in young firms. Administrative Science Quarterly, 60(4), 596-633.

Repullo, R., \& Suarez, J. (2004). Venture capital finance: A security design approach. Review of Finance, $8(1), 75-108$.

Sapienza, H. J. (1992). When do venture capitalists add value? Journal of Business Venturing, 7(1), 9-27.

Schwienbacher, A. (2013). The entrepreneur's investor choice: The impact on later-stage firm development. Journal of Business Venturing, 28(4), 528-545.

Shane, S., \& Cable, D. (2002). Network ties, reputation, and the financing of new ventures. Management Science, 48(3), 364-381.

Sightdx. (2016). Computer vision meets blood diagnostics. Retrieved August 25, 2016, from http://www. sightdx.com/infectious-diseases/parasight/

Stuart, R. W., \& Abetti, P. A. (1990). Impact of entrepreneurial and management experience on early performance. Journal of Business Venturing, 5(3), 151-162.

Sudek, R. (2006). Angel investment criteria. Journal of Small Business Strategy, 17(2), 89-103.

van Osnabrugge, M., \& Robinson, R. (2000). Angel investing: Matching start-up funds with start-up companies. San Francisco, CA: Jossey-Bass.

van Praag, C. M., \& Versloot, P. H. (2007). What is the value of entrepreneurship? A review of recent research. Small Business Economics, 29(4), 351-382.

Wang, S., \& Zhou, H. (2004). Staged financing in venture capital: Moral hazard and risks. Journal of Corporate Finance, 10(1), 131-155.

Wasserman, N. (2006). Stewards, agents, and the founder discount: Executive compensation in new ventures. Academy of Management Journal, 49(5), 960-976.

Wiklund, J., \& Shepherd, D. (2003). Knowledge-based resources, entrepreneurial orientation, and the performance of small and medium-sized businesses. Strategic Management Journal, 24(13), 1307-1314.

Wiltbank, R., \& Boeker, W. (2007). Returns to angel investors in groups. Retrieved March 20, 2015, from http://ssrn.com/abstract $=1028592$

Wiltbank, R., Read, S., Dew, N., \& Sarasvathy, S. D. (2009). Prediction and control under uncertainty: Outcomes in angel investing. Journal of Business Venturing, 24(2), 116-133.

Wong, A., Bhatia, M., \& Freeman, Z. (2009). Angel finance: The other venture capital. Strategic Change, 18(7-8), 221-230. 


\section{Author Biographies}

S. Sinan Erzurumlu is Associate Professor of Technology, Innovation and Operations Management at Babson College. He holds a PhD in Management Science and Information Systems from the McCombs School of Business at the University of Texas at Austin. His research interests are at the confluence of technology and operations management, entrepreneurship, and innovation strategy. In particular, he studies the theory and practice of innovation and entrepreneurship to stimulate technology development, commercialization, and venture growth.

Nitin Joglekar is Associate Professor of Operations \& Technology Management at Boston University Questrom School of Business. He holds a PhD in Management Science from MIT Sloan School of Management. His research interests span digital product management thinking at established firms and for entrepreneurial startups, deployment of analytics and machine learning techniques in innovation processes, as well as digitization and public policy issues in global supply chains.

Moren Lévesque is Professor and the CPA Ontario Chair in International Entrepreneurship at York University Schulich School of Business. She holds a PhD in Management Science from the University of British Columbia. Her research applies the methodologies of analytical and quantitative disciplines to the study of decision making in new business formation. She is interested in market entry decisions, funding decisions, and firm growth decisions, and the impact of time on these entrepreneurial decisions.

Fehmi Tanrisever is Assistant Professor of Operations Management and Finance at Bilkent University Faculty of Business Administration. He holds a $\mathrm{PhD}$ in Supply Chain and Operations Management from the McCombs School of Business at the University of Texas at Austin. His research interests include commodity risk management, operations-finance interface, startup operations, and stochastic programming. 